\title{
1 MATERNAL OBESITY CAUSES FETAL CARDIAC HYPERTROPHY AND ALTERS ADULT OFFSPRING 2 MYOCARDIAL METABOLISM IN MICE
}

4 Owen R. Vaughan ${ }^{1}$, Fredrick J. Rosario ${ }^{1}$, Jeannie Chan ${ }^{2}$, Laura A. Cox ${ }^{2}$, Veronique Ferchaud-Roucher ${ }^{1}$, Karin

5 A. Zemski-Berry ${ }^{3}$, Jane E.B. Reusch ${ }^{3}$, Amy C. Keller ${ }^{3}$, Theresa L. Powell ${ }^{1,4}$ and Thomas Jansson ${ }^{1}$

$6{ }^{1}$ Department of Obstetrics and Gynecology, University of Colorado Anschutz Medical Campus, Aurora, CO, 7 USA

$8 \quad{ }^{2}$ Department of Molecular Medicine, Wake Forest School of Medicine, Winston-Salem, NC, USA

$9{ }^{3}$ Department of Medicine, Division of Endocrinology, Metabolism and Diabetes, University of Colorado 10 Anschutz Medical Campus, Aurora, CO, USA and Rocky Mountain Regional VA Medical Center, Aurora, CO, 11 USA

$12{ }^{4}$ Department of Pediatrics, University of Colorado Anschutz Medical Campus, Aurora, CO, USA

Short title: Maternal obesity alters offspring heart metabolism

Manuscript category: Original article

Correspondence:

17 Owen R. Vaughan, PhD

18 Department of Obstetrics and Gynecology

19 University of Colorado Anschutz Medical Campus

2012700 E19th Avenue

21 Aurora, CO, USA

22 owen.vaughan@CUAnschutz.edu

23 Phone: (303) 724-8622

24 Fax: (303) 724-3512

25

Total word count: 5416 words

Key words: diabetes mellitus, gestational; fetal macrosomia; peroxisome proliferator activated receptor gamma; positron emission tomography; heart failure, diastolic 
Obesity in pregnant women causes fetal cardiac dysfunction and increases offspring cardiovascular disease risk but its effect on myocardial metabolism is unknown. We hypothesised that maternal obesity alters fetal cardiac expression of metabolism-related genes and shifts offspring myocardial substrate preference from glucose towards lipids. Female mice were fed control or obesogenic diets before and during pregnancy. Fetal hearts were studied in late gestation (embryonic day, E18.5; term $\approx E 21$ ) and offspring were studied at 3, 6, 9 or 24 months postnatally. Maternal obesity increased heart weight and peroxisome proliferator activated receptor $\gamma$ (Pparg) expression in female and male fetuses and caused left ventricular diastolic dysfunction in the adult offspring. Cardiac dysfunction progressively worsened with age in female, not male, offspring of obese dams, compared to age-matched controls. In 6-monthold offspring, exposure to maternal obesity increased cardiac palmitoyl carnitine-supported mitochondrial respiration in males and reduced myocardial ${ }^{18} \mathrm{~F}$-fluorodeoxyglucose uptake in females.

42 Cardiac Pparg expression remained higher in adult offspring of obese than control dams and correlated

43 with contractile and metabolic function. Maternal obesity did not affect cardiac palmitoyl carnitine respiration in females or ${ }^{18} \mathrm{~F}$-fluorodeoxyglucose uptake in males, or alter cardiac ${ }^{3} \mathrm{H}$-oleic acid uptake, pyruvate respiration, lipid content or fatty acid/glucose transporter abundance in offspring of either sex. The results support our hypothesis and show that maternal obesity affects offspring cardiac metabolism

47 in a sex-dependent manner. Persistent upregulation of Pparg expression in response to overnutrition in utero may mechanistically underpin programmed cardiac impairments and contribute to cardiovascular disease risk in children of women with obesity. 


\section{INTRODUCTION}

51 The global prevalence of obesity in women of reproductive age is rapidly increasing ${ }^{1}$. Obesity in pregnant

52 women predisposes their children to metabolic syndrome and a range of non-communicable diseases

53 throughout life, thereby placing a substantial burden on the health of the population ${ }^{2}$. Children of women

54 who have obesity during pregnancy are at $30 \%$ greater risk for cardiovascular disease in adulthood ${ }^{3}$. Diet-

55 induced obesity in pregnant animals similarly leads to abnormal cardiovascular function in their adult

56 offspring, irrespective of postnatal diet ${ }^{4,5}$, demonstrating that lifelong phenotype is programmed before

57 birth. However, the mechanisms underlying cardiometabolic programming by maternal obesity remain

58 poorly understood and neither the specific programming signals nor their primary targets in the fetus

59 have been clearly identified.

60 Fetuses of obese women have cardiac hypertrophy and contractile dysfunction as early as the first

61 trimester $^{6,7}$, and these abnormalities persist at least into childhood ${ }^{8}$. Similarly, in experimental animals,

62 maternal obesity increases fetal heart size, wall thickness, cardiomyocyte size, inflammation and collagen

63 content, and impairs contractility ${ }^{9-12}$. These data suggest that maternal obesity directly affects the heart

64 in utero.

65 Maternal obesity alters placental transport and fetal delivery of glucose and lipids, in both humans and experimental animals ${ }^{13-16}$. Maternal obesity also increases fetal cardiac lipid storage in sheep ${ }^{11}$, and

67 impairs glucose uptake and mitochondrial respiration in isolated cardiomyocytes from the offspring in

68 rodents ${ }^{17,18}$. Impaired diastolic function in people with diabetes is associated with increased cardiac fatty

69 acid uptake and oxidation, but reduced glucose uptake ${ }^{19,} 20$ whilst genetic modifications that increase

70 cardiac lipid uptake in mice cause contractile dysfunction ${ }^{21}$. Whether abnormal cardiac glucose and lipid

71 metabolism contributes to cardiac dysfunction in the offspring of pregnancies complicated by maternal

72 obesity remains unknown. 
73 We have developed a mouse model of maternal obesity associated with fetal overgrowth that closely

74 replicates the phenotype of obese pregnant women in terms of maternal physiology, placental nutrient

75 transport and fetal growth ${ }^{13}$. In this model, administration of adiponectin to increase maternal

76 concentrations of this metabolic hormone in obese dams, to the levels observed in control animals,

77 normalises placental nutrient transport, prevents fetal overgrowth and mitigates cardiac diastolic

78 dysfunction in the adult offspring ${ }^{22,23}$. In the current study, we used our established model to determine

79 the effect of maternal obesity on the fetal cardiac transcriptome and on cardiac contractile and metabolic

80 function in the adult offspring. We hypothesised that maternal obesity alters fetal cardiac expression of

81 metabolism-regulating genes and increases lipid metabolism but reduces glucose metabolism in hearts of

82 adult offspring. We also measured cardiac histone acetylation, which is linked to heart failure ${ }^{24}$ and is

83 sensitive to nutrient availability ${ }^{25}$, to determine whether it plays a role in fetal cardiac programming by

84 maternal obesity. 
Animals

87 All procedures were conducted with approval from the Institutional Animal Care and Use Committee of the University of Colorado. Female C57BL6/J mice, proven breeders, were fed ad libitum with an obesogenic diet $(\mathrm{Ob}, \mathrm{n}=31)$ consisting of high fat pellets (Western Diet D12079B, $41 \mathrm{kcal \%}$ fat) supplemented with sucrose solution (20\%), or a control diet (Con, D12489B, 10.6 kcal\% fat, $n=50$ ). All animals had ad libitum access to fresh water and were housed under standard $12 \mathrm{hr}: 12 \mathrm{hr}$ dark:light conditions. When females fed the Ob diet had gained $25 \%$ of their initial body weight, they were mated overnight with stud males. Age-matched Con females were mated simultaneously. Successful mating was confirmed by the presence of a copulatory plug the following morning, designated embryonic day (E) 0.5 (term E19.5). Pregnant females were subsequently housed in pairs. On E18.5, a subset of Con $(n=5)$ and $\mathrm{Ob}(\mathrm{n}=5)$ dams were euthanised by $\mathrm{CO}_{2}$ asphyxiation and cervical dislocation. The uterus was exposed,

97 fetuses were excised and weighed then their hearts were dissected, weighed and snap frozen in liquid $\mathrm{N}_{2}$.

98 A fetal tail snip was also collected for subsequent determination of sex, by Zfy-1 genotyping ${ }^{26}$. The remaining Con and $\mathrm{Ob}$ dams delivered naturally at term and continued to consume their respective diets throughout lactation, until all pups were weaned onto standard chow at age 4 weeks. Pups were subsequently housed in same sex groups, from multiple litters. In total, 187 offspring were used in the 102 study.

Echocardiography. Cardiac structure and function were assessed using transthoracic echocardiography in 105 a subset of offspring at both 3 and 6 months of age (females $n=10$ Con, 6 Ob; males $n=7$ Con, 7 Ob), as described in Supplemental Methods. One week after the second echocardiography assessment, offspring

107 were fasted for $4 \mathrm{hr}$ then euthanised by $\mathrm{CO}_{2}$ asphyxiation and cervical dislocation. Hearts were perfused 
with PBS then excised and weighed. The left ventricle was dissected and snap frozen in liquid $\mathrm{N}_{2}$ for gene expression analyses. Thirty-nine additional animals that had not undergone echocardiography were also euthanised at age 6 months, and tissues collected in the same manner for gene expression and lipidomic

111 analyses.

112 Separate cohorts of offspring underwent echocardiographic assessment by the same operator at ages 9 113 months $(n=28)$ or 24 months $(n=22)$, without being imaged at earlier time points. These animals were 114 euthanised seven days after echocardiography and their tissues collected for use in other studies.

Positron emission tomography. Cardiac glucose uptake was assessed in vivo in forty-eight 6-month old offspring using positron emission tomography (PET) with ${ }^{18} \mathrm{~F}$-fluorodeoxyglucose $\left({ }^{18} \mathrm{~F}-\mathrm{FDG}\right)$ tracer. Animals

117 were fasted for 4 hours prior to the study then anaesthetised ( $2 \%$ isoflurane, inhaled) and positioned in 118 dorsal recumbency on a warming pad at $37^{\circ} \mathrm{C}$. Animals were then placed inside a PET imaging system 119 (Inveon microPET, Siemens Medical, Knoxville, TN, USA) and a bolus dose of ${ }^{18} \mathrm{~F}$-FDG was administered 120 intravenously, to the tail vein (250uCi). Fifteen dynamic PET image frames were collected at successive 121 timepoints over a period of 35 minutes. A whole-body computerised tomography image, without contrast 122 agent, was subsequently collected to confirm anatomical distribution of the ${ }^{18} \mathrm{~F}$-FDG tracer. Mice were 123 removed from the scanner, recovered from anaesthesia and housed in a lead-shielded cage with ad 124 libitum access to food and water, before being returned to their home cage $24 \mathrm{hr}$ later.

125 Ten animals that underwent PET imaging were excluded from the subsequent analysis because (a) they 126 did not tolerate anaesthesia, (b) poor tail vein patency hindered tracer infusion, or (c) movement 127 interfered with collection of dynamic frame images. Dynamic frame PET images were assembled for each 128 animal and voxel intensities (radioactivity) determined for manually defined regions of interest in the left 129 ventricular myocardium (study compartment) and lumen (reference compartment). Radioactivity at each timepoint, within each compartment, was corrected for decay, animal weight and the amount of tracer 
131 injected. The ratio of radioactivity in the left ventricular myocardium to that in the reference compartment

132 was then plotted against normalised time from tracer injection, according to the Patlak method ${ }^{27}$.

133 Separate linear regression lines were fitted to data from Con and Ob groups and the slopes compared by

134 extra sum-of-squares $\mathrm{F}$ test, within each sex. The slope of the Patlak plot represents the clearance of ${ }^{18} \mathrm{~F}-$

135 FDG from the blood, into the myocardium.

136 This group of animals was euthanised seven days after imaging, as described above. A portion of the left

137 ventricle was placed into ice-cold biopsy preservation solution (BIOPS ${ }^{28}$ ) for analysis of mitochondrial

138 respiration within $\sim 3$ hours.

In vivo left ventricular ${ }^{3} \mathrm{H}$-oleic acid uptake. Cardiac fatty acid uptake was quantified in 20 six-month old offspring using a radioactive tracer, as described previously ${ }^{29}$. Briefly, $4.5 \mu \mathrm{Ci}{ }^{3} \mathrm{H}$-oleic acid (NET289001MC,

142 free bovine serum albumin to a final volume of $200 \mu \mathrm{l}$, at $37^{\circ} \mathrm{C}$ with shaking. Mice were anaesthetised

143 with ketamine and xylazine (i.p.), the tail vein canulated and the BSA-complexed ${ }^{3} \mathrm{H}$-oleic acid tracer 144 delivered as a bolus. Up to five minutes later, mice were euthanised with sodium pentobarbital solution

145 (i.v.), rapidly exsanguinated and the heart perfused with PBS. Plasma was separated from blood by 146 centrifugation. Left ventricles (LV) were dissected, weighed then digested for $48 \mathrm{hr}$ at $50^{\circ} \mathrm{C}$ in Biosol

147 (National Diagnostics). LV and plasma radioactivity were determined by liquid scintillation counting and

$148{ }^{3} \mathrm{H}$-oleic acid clearance calculated from the ratio of total LV counts to the area under the curve of plasma 149 counts versus time from tracer infusion, divided by LV weight.

151 RNA extraction, sequencing and Ingenuity Pathway Analysis. Heart tissues were collected from male and 152 female fetuses within litters from $\operatorname{Con}(n=5)$ and $\mathrm{Ob}(n=5)$ dams and stored at $-80^{\circ} \mathrm{C}$. Individual frozen 153 tissue samples ( $10 \mathrm{mg}$ ) were homogenized in TRI Reagent and total RNA was isolated using Direct-zol 
RNA MiniPrep kits (Zymo Research, Irvine, CA) according to the manufacturer's instructions. After eluting

155 RNA from the Zymo-Spin column in $50 \mu \mathrm{l}$ DNase/RNase-free water, RNA quality was assessed using an

Agilent 2100 Bioanalyzer (Agilent Technologies, Inc., Santa Clara, CA). RNA concentration was quantified

Total RNA was stored at $-80^{\circ} \mathrm{C}$. Differentially expressed genes between Con and Ob fetuses were identified and functionally annotated, as described in the Supplementary Methods.

High resolution in situ respirometry. Carbohydrate- and lipid supported rates of mitochondrial respiration were assessed in cardiac muscle from 6-month old offspring, using high resolution respirometry. Biopsies of fresh left ventricular tissue in ice-cold BIOPS solution were dissected under magnification into myofiber bundles of approximately $1 \mathrm{mg}$. The sarcolemmal membrane was permeabilized by incubating in saponin solution (40 $\left.\mu \mathrm{g} \mathrm{ml}^{-1}, 20 \mathrm{~min}\right)$ then washed, accurately weighed and placed in an oxygraph chamber (Oroboros O2k Respirometer), in respiration medium (MIRO5, ${ }^{28}$ ) with blebbistatin $(5 \mathrm{mM})$ to inhibit muscle contraction. Medium was equilibrated with $\mathrm{O}_{2}$ gas to an initial dissolved concentration of $400 \mu \mathrm{M}$ and the chamber was sealed. Catalase was also added to the respiration medium to allow liberation of oxygen by $\mathrm{H}_{2} \mathrm{O}_{2}$ addition during the experiment, thus retaining dissolved $\mathrm{O}_{2}$ concentration between 300 $\mu \mathrm{M}$ and $400 \mu \mathrm{M}$.

171 of substrates and inhibitors, designed to determine the basal and maximal rates of carbohydrate- and

172 lipid-supported respiration, respectively. In the first assay, pyruvate $(5 \mathrm{mM})$ and malate $(2 \mathrm{mM})$ were

173 added to the oxygraph chamber to supply the electron transport chain via reduced intermediates

174 generated in the citric acid cycle. In the second assay, palmitoyl carnitine $(5 \mu \mathrm{M})$ and malate $(1 \mathrm{mM})$

175 supplied electrons via mitochondrial $\beta$-oxidation. In both cases, leak state oxygen consumption was first 176 measured in the absence of ADP. Then ADP $(2 \mathrm{mM})$ was introduced to measure basal respiration rate, 177 coupled to ATP synthase activity. Glutamate $(3 \mathrm{mM})$ and succinate $(6 \mathrm{mM})$ were subsequently provided to 
support direct electron flux to complex I and II of the electron transport chain, allowing maximum oxidative phosphorylation capacity to be measured. ATP synthase activity was abolished using oligomycin $(4 \mu \mathrm{g} / \mathrm{ml})$, to measure leak state oxygen consumption supported by both fatty acid oxidation and direct complex I/II electron entry. Finally, FCCP (carbonyl cyanide 4-(trifluoromethoxy)phenylhydrazone) was added in increments of $0.5 \mu \mathrm{M}$ to permeabilise the inner mitochondrial membrane, until maximal, uncoupled oxygen consumption was achieved, measuring electron transport chain capacity. Respiration rates were corrected to fresh tissue mass. Coupling efficiencies for each of the two combinations of substrates was calculated as 1 minus the ratio (leak state respiration/maximal electron transport chain capacity).

Targeted lipidomic analyses. Cardiac triglyceride contents were determined by colorimetric assay (MAK266, Sigma-Aldrich). Myocardial content of individual fatty acids, ceramides and diacylglycerol species was measured in adult offspring using targeted mass spectrometry, described in Supplementary Methods.

Western blot. Fatty acid and glucose transporter protein abundance was measured in cardiac tissue from 6-month old offspring using western blotting. Frozen heart samples were homogenised in hepes-tris buffered saline with protease and phosphatase inhibitors (Sigma Aldrich). Samples were then loaded in Laemmli buffer, resolved by polyacrylamide gel electrophoresis and transferred to polyvinylidene fluoride membrane. Membranes were incubated with primary antibodies to CD36, FATP1, FATP6, GLUT1 and GLUT4 then with a horseradish peroxidase linked secondary antibody and visualised using enhanced chemiluminescence reaction and a gel imaging system. Protein abundance was determined by densitometry of specific bands, corrected for protein loading (amido black stain).

Gene expression. Cardiac expression of selected mRNAs related to lipid metabolism was determined in a targeted manner using qRT-PCR. RNA was extracted from frozen ventricular tissue from 6-month-old Con 
201 (females $n=9$, males $n=11$ ) and Ob (females $n=10$, males $n=10$ ) offspring using a commercially available kit

202 (RNeasy Plus mini Kit, Qiagen) then reverse transcribed to cDNA (High Capacity cDNA Reverse

203 Transcription kit, Applied Biosystems). Relative expression of target mRNAs was determined by qRT-PCR

204 using SYBR Green chemistry and forward and reverse primers, as detailed in Supplemental Table 1. The

205 efficiency of all primer pairs was confirmed to be between 80 and $110 \%$ by calculating the linear gradient

206 of the relationship between average Ct value and dilution factor for a 5-fold serially diluted standard curve

207 of pooled cDNA. PCR product size was validated by agarose gel electrophoresis. Gene expression was

208 determined relative to the geometric mean of Rna18s and Rps29 expression using the ddCt method.

209 Statistics. Results are presented as mean \pm SEM. All statistical analyses were conducted separately in

210 female and male offspring. Normality of data was assessed by Shapiro-Wilk test. Echocardiographic

211 measurements of cardiac function and morphometry were analysed by two-way ANOVA, with maternal

212 obesity and postnatal age as independent factors. When there was a significant interaction between these

213 two factors, the simple effect of maternal obesity at each age was assessed by Sidak post-hoc test. For all

214 other measurements, Con and Ob groups were compared by Student's t-test or by Mann-Whitney test, if

215 data did not conform to a normal distribution. Analyses of lipidomic data were corrected for multiple

216 comparisons using the Holm-Sidak method. Linear relationships between variables were determined by

217 Pearson's correlation. In all cases, significance was taken at the level $P<0.05$. 


\section{1 lipid metabolism genes}

222 Maternal obesity increased fetal heart weight at E18.5, as a percentage of total body weight, in both male

223 and female fetuses (Fig. 1A, B). Absolute heart and body weights were also greater in fetuses of obese 224 dams, compared to controls (Table 1).

225 Maternal obesity concomitantly altered the expression of 841 genes in the hearts of female fetuses and 764 genes in the hearts of male fetuses, with 66 genes commonly altered in both sexes (Suppl. Fig. 1A, B).

227 Ingenuity analysis predicted inhibition of processes related to neoplasia and DNA repair/synthesis in male

228 fetal hearts, and pathways related to function, quantity and movement of immune cells in female fetal 229 hearts, in obese compared to control dams (z-score <-1.7, top ten functions by P-value, Fig. 1C, D). By 230 contrast, maternal obesity activated synthesis of lipid and metabolism of membrane lipid derivatives in 231 male fetuses, and uptake of monosaccharides and carbohydrates in female fetuses (activation z-score > 232 1.7, top-ten functions by P-value, Fig. 1 E, F). Transport of molecules was consistently activated by 233 maternal obesity in both males and females (Fig. 1G).

234 The activated downstream functions related to molecular transport, carbohydrate and lipid metabolism encompassed an overlapping suite of differentially expressed genes, several of which were commonly regulated by maternal obesity in male and female fetuses (Fig. $1 \mathrm{H}$ ). Specifically, maternal obesity upregulated Pparg, the nuclear peroxisome proliferator activated receptor implicated in lipogenesis, Cd36, a plasma membrane fatty acid translocase, and Prkaa1, the catalytic subunit of cytoplasmic AMPactivated protein kinase (AMPKa1), in fetuses of both sexes (Fig. 1H-J). Network analysis of direct 
242 Furthermore, when unsupervised regulator effects analysis was used to link the annotated downstream

243 functions of differentially expressed genes to upstream effectors, a network of genes activated by

244 Ppargc1a and including Cd36 and the triglyceride synthesis enzyme, Lpin1, was predicted to promote lipid

245 synthesis in male fetal hearts in response to maternal obesity (Suppl. Fig 1E.). Taken together, the

246 transcriptomic data were most consistent with maternal obesity promoting cardiac lipid metabolism in

247 male and female fetuses, by increasing expression of genes related to fatty acid uptake, lipid synthesis

248 and oxidation.

Maternal obesity in pregnant mice causes age- and sex-dependent diastolic dysfunction and left ventricular dilation in adult offspring.

251 In male offspring, E/A and $E^{\prime} / A^{\prime}$ ratios of left ventricular diastolic function declined overall with increasing 252 postnatal age from 3 to 24 months and were further impaired by maternal obesity at all time points (Fig.

$2532 \mathrm{~A}, \mathrm{C})$. Maternal obesity also reduced E/E' ratio in males, with significant differences apparent between

254 Con and Ob groups in both the youngest and oldest offspring studied (Fig. 2E). By contrast, the effect of 255 maternal obesity on diastolic function in female offspring depended on the age at which they were 256 studied. Three months after birth, neither $E / A$ nor $E^{\prime} / A^{\prime}$ ratio differed between Con and Ob female 257 offspring (Fig 2B, D). Six months after birth, E'/A' ratio, but not E/A ratio, was reduced, and by 9 months 258 both $E^{\prime} / A^{\prime}$ and E/A ratios were lower in Ob compared to Con females. Finally, at age 24 months, E/A ratio 259 was higher in $\mathrm{Ob}$ than Con female offspring, whereas $E^{\prime} / A^{\prime}$ ratio was similar in the two groups, indicating 260 a more severe state of diastolic dysfunction with pseudonormal filling pattern. E/E' ratio was lower in Ob 261 than Con female offspring, irrespective of age (Fig. 2F). Therefore, maternal obesity caused diastolic 262 dysfunction in adult offspring of both sexes, albeit the effect was later in onset but faster in progression 263 in females than males. 
In males, maternal obesity increased end-diastolic volume in 2-year-old offspring and increased endsystolic volume irrespective of age (Fig. 3A, C). By contrast, in female offspring, maternal obesity increased left ventricular end-diastolic volume, but not end-systolic volume (Fig. 3B, D). Both left ventricular wall thickness and systolic function, measured by ejection fraction and fractional shortening, increased modestly with age in male and female mice but were not affected by maternal obesity (Suppl. Fig 2). When tissues were weighed at necropsy in 6-month old offspring, heart weight was significantly greater in Ob than Con females as an unadjusted value, but not expressed as a percentage of body weight (Table 2).

271 However, none of the other measurements of body, heart or ventricle weight differed between Con and 272 Ob offspring at this age.

Maternal obesity alters cardiac metabolism in adult offspring in a sex-specific manner

Gene expression. Maternal obesity upregulated Pparg expression in both male and female 6-month old offspring of obese dams, compared to controls (Fig. 4A, B). Cd36 and Prkaa1 expression were also higher in Ob than Con male offspring hearts, but not in females (Fig. 4). In male offspring, maternal obesity increased expression of downstream Pparg targets related to lipid synthesis and storage (Fasn, Plin2, Srebp1) and lipid oxidation (Pgc1a, Cpt1b, Acox1) but did not alter Pgc1b, Cpt1a, Mcad, Hoad, Pdk4 or 279 Ucp3 expression (Fig. 4A). In female offspring, maternal obesity upregulated Fasn but did not affect expression of any of the other downstream mediators of lipid metabolism studied (Fig. 4B). When adult male offspring from control and obese dams were combined, there was a strong inverse correlation between cardiac Pparg gene expression and E/E' ratio (Fig. 4C). In female offspring, there was a strong correlation between cardiac Pparg expression and left-ventricular end-diastolic volume (Fig. 4D). Cd36 expression in female offspring also positively correlated with E/A ratio and inversely correlated with wall thickness at diastole, whilst both Pdk4 and Hoad expression correlated with wall thickness at systole and end-diastolic volume (Suppl. Table 2). There were no other significant correlations between cardiac gene expression and the measured echocardiographic and morphometric outcomes in adult offspring (Suppl. 
Table 2). Therefore, transcriptional upregulation of Pparg expression and lipid metabolism persisted in the offspring of obese dams and was linked to cardiac functional and structural phenotype in male and female offspring.

Lipid metabolism. Left ventricular ${ }^{3} \mathrm{H}$-oleic acid clearance in vivo was greater in female than male offspring of control dams (Suppl. Fig. 3A). However, cardiac fatty acid clearance did not differ significantly between Ob offspring and their Con counterparts of the same sex (Fig. 5A, B). Maternal obesity reduced FATP6 transporter protein abundance in hearts of female, but not male offspring, and did not affect CD36 or FATP1 protein abundance (Table 3).

In male offspring, maternal obesity increased cardiac palmitoyl carnitine respiration in the leak state (+oligomycin), when palmitoyl carnitine was supplied in combination with malate, glutamate and succinate (Fig. 5C). Maximal oxidative phosphorylation-coupled palmitoyl carnitine respiration and electron transport chain capacity (+FCCP) also tended to be higher in Ob than Con male offspring hearts (Fig. 5C). However, maternal obesity had no effect on either coupled or leak respiration supported by palmitoyl carnitine alone in male offspring (Fig. 5C), or on any of the rates of fatty acid supported respiration in female offspring hearts (Fig. 5D). The coupling efficiency of fatty acid supported respiration correlated with cardiac Pparg expression in male offspring (Fig. 5E). However, there were no overall differences in coupling efficiency between Con and Ob offspring (Suppl. Table 3).

Maternal obesity did not alter adult offspring cardiac fatty acid content (Suppl. Table 4) or triglyceride content (females Con $7.7 \pm 2.2 \mu \mathrm{g} / \mathrm{mg}$, Ob $9.3 \pm 2.2 \mu \mathrm{g} / \mathrm{mg}$; males Con $22.9 \pm 5.0 \mu \mathrm{g} / \mathrm{mg}$, Ob $32.7 \pm 6.2$ $\mu \mathrm{g} / \mathrm{mg}$ ). Maternal obesity reduced offspring cardiac 1,2-18:2/18:1 DAG content but did not alter abundance of the other DAGs measured in adult male offspring and had no effect on any of the DAGs in female offspring hearts (Suppl. Table 5). There was no difference in ceramide content between Con and Ob offspring (Suppl. Table 6). 
311 Carbohydrate metabolism. Myocardial glucose uptake, determined using PET as the rate of clearance of

$312{ }^{18} \mathrm{~F}$-deoxyglucose from plasma into the left ventricle, was greater in male than female control offspring

313 (Suppl. Fig. 3B, C). Maternal obesity reduced myocardial glucose uptake in female but not male offspring

314 (Fig. 6A-D) but did not alter cardiac GLUT1 or GLUT4 abundance in offspring of either sex (Table 3). There

315 were no differences between Con and Ob offspring in the rates of pyruvate-supported mitochondrial

316 respiration in cardiac muscle ex vivo (Fig. 6E, F). Similarly, neither histone H3 protein abundance nor

317 acetylation differed between Con and Ob offspring (Fig. 7).

318 
321 This is the first study in mice to link the effects of maternal obesity on fetal cardiac morphology and gene 322 expression with alterations in cardiac contractile and metabolic function in the adult offspring. The results 323 show that maternal obesity causes fetal cardiac hypertrophy in utero, in association with transcriptomic 324 changes consistent with altered cardiac carbohydrate and lipid metabolism. We also report that maternal 325 obesity impairs cardiac diastolic function in both male and female adult offspring, up to 2 years after birth, 326 but the progression of cardiac dysfunction with age is sex dependent. The impairments in contractile 327 function were accompanied by persistent Pparg upregulation and altered carbohydrate and lipid 328 metabolism in female and male offspring, respectively. The study therefore indicates that cardiac 329 metabolism is programmed by in utero exposure to maternal obesity and contributes to cardiac 330 dysfunction in later life.

331 The hypertrophic effects of maternal obesity on fetal heart and left ventricle weight were similar in female 332 and male fetuses and consistent with that reported previously in other experimental animals ${ }^{9-12}$ and 333 pregnant women ${ }^{6,7}$. In contrast, the effect on the fetal cardiac transcriptome strongly depended on fetal 334 sex, with less than $10 \%$ of the differentially expressed genes shared between females and males. Based 335 on bioinformatic analysis of the differentially expressed genes, the gross hypertrophic effect did not 336 appear to be explained by cellular processes that were transcriptionally inhibited in response to maternal 337 obesity, which were broadly related to inflammation in female fetuses and cell proliferation in male 338 fetuses. These changes could be linked to myocardial fibrotic remodelling ${ }^{10,11}$ or impaired cardiomyocyte 339 endowment, depending on fetal sex. However, the processes that were transcriptionally activated 340 seemed more likely to contribute to cardiac hypertrophy, because they were associated with transport, 341 uptake, synthesis and metabolism of macronutrient molecules required for cell growth and contractile 342 function. Certainly, cardiac lipid and glucose metabolism are strongly linked to cardiac dysfunction in obese and diabetic adults 19,20 . 
344 Our bioinformatic analysis pointed to Pparg as a central node in the network of differentially expressed

345 genes related to metabolism. Cardiac Pparg was upregulated in both female and male fetuses of obese

346 dams, consistent with previous reports in liver and skeletal muscle from fetuses of pregnant macaques

347 fed a high fat diet ${ }^{30,31}$. The PPAR p protein is a transcription factor that is activated by binding with fatty

348 acid ligands and drives the expression of genes mediating fatty acid uptake and oxidation, including fatty

349 acid translocase $C d 36$, which was also upregulated in fetuses of obese dams. Pparg mRNA expression is

350 upregulated in adult mice fed a high fat diet ${ }^{32}$ and cardiomyocyte-specific overexpression of Pparg causes

351 cardiac hypertrophy in transgenic adult mice, in association with systolic dysfunction, abnormal

352 mitochondrial architecture, increased triglyceride uptake and lipid storage and increased expression of

353 genes encoding for proteins involved in $\beta$-oxidation ${ }^{21}$. Our previous study showed that maternal obesity

354 increases placental lipid transport and fetal lipid load in mice ${ }^{33}$. Therefore, fetal cardiac hypertrophy in

355 pregnancies complicated by maternal obesity may be promoted by increased circulating fatty acid

356 availability activating PPARy signalling in the heart.

357 The finding that maternal obesity impairs diastolic function in adult offspring up to 2 years old extends

358 our previous observations in this model ${ }^{23}$. These data confirm that transient cardiac hypertrophy due to

359 excess nutrition in early life leads to lasting impairments in contractile function of the heart, in common

360 with other studies in mice and their isolated cardiomyocytes ${ }^{5,18}$. Since systolic function was not affected

361 by maternal obesity, the echocardiographic observations in offspring of obese dams were most consistent

362 with the phenotype of heart failure with preserved ejection fraction, which is a significant cause of

363 cardiovascular mortality in people ${ }^{34}$. Mild diastolic dysfunction is often subclinical and not diagnosed as

364 heart failure, but still associated with increased mortality. Our data therefore suggest diastolic dysfunction

365 or heart failure could be a contributing factor to increased later life cardiovascular morbidity in people

366 whose mothers had obesity during pregnancy ${ }^{3}$. To our knowledge, there have been no studies of adult

367 cardiac function in this population. 
In contrast with the changes in fetal heart weight, the effect of maternal obesity on offspring cardiac

369 function depended on postnatal age and sex, with diastolic function consistently impaired in males but

370 progressively worsening with age in females. This may be partly explained by circulating oestrogens

371 having a cardioprotective effect in young female offspring ${ }^{35}$. The appearance of overt diastolic

372 dysfunction in 9-month old offspring of obese dams, with both $E^{\prime} / A^{\prime}$ and $E / A$ ratios reduced,

373 approximately coincided with declining oestradiol levels in this strain and may therefore reflect

374 diminishment of the protective oestrogen effect ${ }^{36}$. Unfortunately, we did not consider the influence of

375 reproductive cycles in the timing of our analyses and blood collections, preventing us from further

376 investigating the contribution of oestradiol levels. Female offspring of obese dams had most severe

377 diastolic dysfunction at 2 years of age, which is certainly after full reproductive senescence occurs

378 between 13 and 16 months ${ }^{37}$. Sex differences in the long-term effect of maternal obesity on the offspring

379 heart could therefore be due to sexually dimorphic changes in normal physiology and endocrinology with

380 age. This is consistent with clinical observations showing that elderly women have a higher risk of cardiac

381 dysfunction than men and are more likely to develop dysfunction in association with type 2 diabetes and

382 ventricular hypertrophy ${ }^{38}$.

Our study suggests that the sex-specific effects of maternal obesity may also be linked to differences in

384 the metabolism of the heart. The results provide the first demonstration that in vivo cardiac metabolism

385 depends on sex in adult mice, with greater cardiac fatty acid uptake in females but greater glucose uptake

386 in males, in line with the known differences between women and men ${ }^{39,40}$. Reduced in vivo cardiac

387 glucose uptake in adult female offspring of obese dams is consistent with the reported reduction in in

388 vitro cardiomyocyte glucose uptake when the offspring of obese mice are fed a high fat diet ${ }^{18}$. It also

389 reflects the pathophysiological changes in the hearts of people with type 2 diabetes ${ }^{19}$. Since there was no 
resistance in female offspring of obese dams. Maternal obesity has been shown to cause peripheral insulin resistance, reduced cardiac insulin receptor abundance and sex-specific alterations in signalling pathways downstream of the insulin receptor in the offspring heart ${ }^{4,23}$. In turn, impaired glucose uptake may have limited cardiac flexibility to generate ATP under conditions of high workload or low oxygen, causing contractile dysfunction. Certainly, glucose uptake is positively correlated with systolic function in humans 41.

Alterations in net cardiac lipid uptake did not explain diastolic dysfunction in the offspring of obese dams, even though myocardial fatty acid uptake has been reported to increase in association with diastolic dysfunction in people with diabetes ${ }^{19}$. Cardiac dysfunction in adult male offspring in our study may

401 instead have been related to the increase in mitochondrial fatty acid oxidation, which similarly occurs in 402 association with reduced energetic efficiency in the hearts of adult rats fed a high fat diet ${ }^{42}$. This effect 403 may partly be mediated by increased expression of PPARY co-activator $1 \alpha$ (Pgc1a), which stimulates 404 mitochondrial biogenesis, and the carnitine acetyltransferase $C p t 1 b$, responsible for trafficking long chain 405 fatty acids into the mitochondria. Although our observations indicated that maternal obesity most 406 robustly increased oligomycin-uncoupled $\beta$-oxidation, there was no accompanying increase in Ucp3 407 expression or coupling control ratio, suggesting that the effect of maternal obesity was primarily due to 408 increased activity of the $\beta$-oxidation pathway itself. Increased lipid oxidation in offspring of obese dams 409 may have caused cardiomyocyte damage by increasing production of reactive oxygen species ${ }^{17}$. Despite 410 increased Plin2 and Srebp1 expression in males, we did not find evidence of increased cardiac lipid storage 411 or altered abundance of DAG and ceramide derivatives, arguing against a role for cardiac lipotoxicity per 412 se in the offspring of obese dams. This finding contrasted with previous studies in sheep fetuses and 413 neonatal rats showing that maternal obesity increases cardiac lipid accumulation in the perinatal period $4149,17$. Increased lipid oxidation may therefore outweigh increased storage in the long term. Indeed, cardiac 415 triglyceride content is reduced in adult offspring of pigs fed a high fat diet ${ }^{43}$. The results are therefore 
most consistent with increased lipid oxidation underpinning cardiac dysfunction in male offspring of obese

417 dams.

418 At a molecular level, increased cardiac lipid oxidation was consistent with the persistant upregulation of

419 Pparg expression, compared to controls. We therefore speculate that Pparg upregulation causes the 420 myocardial metabolic alterations and, in turn, diastolic dysfunction in the adult male offspring. This

421 proposal is supported by the strong correlation of Pparg expression with E/E' ratio and respiratory

422 coupling control ratio in adult male offspring. Pparg expression is strongly linked to increased locus

423 specific $\mathrm{H} 3 \mathrm{~K} 9$ and $\mathrm{H} 3 \mathrm{~K} 27$ acetylation during adipogenesis ${ }^{44}$ and maternal high fat feeding increases fetal

424 hepatic Pparg expression in association with increased histone acetylation ${ }^{45}$ but we did not find any

425 changes in total cardiac H3K9 and H3K27 acetylation in this study. Therefore, the epigenetic mechanism

426 underpinning persisting upregulation of Pparg in the offspring of obese dams remains unclear.

427 Taken together, the results support our hypothesis that maternal obesity alters cardiac metabolism in

428 fetuses and adult offspring of obese pregnant mice. They show that the long-term effects are sex-specific

429 but associated with cardiac Pparg upregulation and a shift from glucose to lipid metabolism in both male

430 and female offspring of obese dams. Reduced cardiac metabolic flexibility, established in utero, may

431 therefore contribute to later-life cardiometabolic disease risk in children of women with obesity. The

432 findings imply that therapeutic strategies that modify the supply of nutrients to fetuses of obese women

433 may improve their later health. 


\section{FUNDING}

436 This work was supported by the Eunice Kennedy Shriver National Institute for Child Health and Human

437 Development and National Center for Advancing Translational Sciences at the National Institutes of Health

438 [grant numbers R24OD016724, R01HD065007, UL1 TR002535]. Lipidomics services were performed by

439 the University of Colorado Nutrition Obesity Research Center Lipidomics Core Facility supported by

440 National Institute of Diabetes and Digestive and Kidney Diseases [grant Number DK048520]. Contents are

441 the authors' sole responsibility and do not necessarily represent official NIH views.

\section{CONFLICT OF INTEREST}

443 Conflict of Interest: none declared 


\section{REFERENCES}

446 1. Poston L, Caleyachetty R, Cnattingius S, Corvalan C, Uauy R, Herring S, Gillman MW.

1. Poston L, Caleyachetty R, Cnattingius $S$, Corvalan $C$, Uauy $R$, Herring $S$, Gillman $M W$. Preconceptional and maternal obesity: epidemiology and health consequences. The lancet Diabetes \& endocrinology 2016;4:1025-1036.

2. Godfrey KM, Reynolds RM, Prescott SL, Nyirenda M, Jaddoe VWV, Eriksson JG, Broekman BFP. Influence of maternal obesity on the long-term health of offspring. The Lancet Diabetes \& Endocrinology;5:53-64.

3. Reynolds RM, Allan KM, Raja EA, Bhattacharya S, McNeill G, Hannaford PC, Sarwar N, Lee AJ, Bhattacharya S, Norman JE. Maternal obesity during pregnancy and premature mortality from cardiovascular event in adult offspring: follow-up of 1323275 person years. Bmj 2013;347:f4539.

4. Fernandez-Twinn DS, Blackmore HL, Siggens L, Giussani DA, Cross CM, Foo R, Ozanne SE. The programming of cardiac hypertrophy in the offspring by maternal obesity is associated with hyperinsulinemia, AKT, ERK, and mTOR activation. Endocrinology 2012;153:5961-5971.

5. Loche E, Blackmore HL, Carpenter AAM, Beeson JH, Pinnock A, Ashmore TJ, Aiken CE, de AlmeidaFaria J, Schoonejans J, Giussani DA, Fernandez-Twinn DS, Ozanne SE. Maternal Diet-Induced Obesity Programmes Cardiac Dysfunction in Male Mice Independently of Post-Weaning Diet. Cardiovasc Res 2018;114:1372-1384.

6. Ingul CB, Loras L, Tegnander E, Eik-Nes SH, Brantberg A. Maternal obesity affects fetal myocardial function as early as in the first trimester. Ultrasound in obstetrics \& gynecology : the official journal of the International Society of Ultrasound in Obstetrics and Gynecology 2016;47:433-442.

7. Ece I, Uner A, Balli S, Kibar AE, Oflaz MB, Kurdoglu M. The Effects of Pre-pregnancy Obesity on Fetal Cardiac Functions. Pediatric Cardiology 2014;35:838-843.

8. Toemen L, Gishti O, van Osch-Gevers L, Steegers EA, Helbing WA, Felix JF, Reiss IK, Duijts L, Gaillard $\mathrm{R}$, Jaddoe VW. Maternal obesity, gestational weight gain and childhood cardiac outcomes: role of childhood body mass index. International journal of obesity (2005) 2016;40:1070-1078.

9. Fan X, Turdi S, Ford SP, Hua Y, Nijland MJ, Zhu M, Nathanielsz PW, Ren J. Influence of gestational overfeeding on cardiac morphometry and hypertrophic protein markers in fetal sheep. $J$ Nutr Biochem 2011;22:30-37.

10. Huang Y, Yan X, Zhao JX, Zhu MJ, McCormick RJ, Ford SP, Nathanielsz PW, Ren J, Du M. Maternal obesity induces fibrosis in fetal myocardium of sheep. Am J Physiol Endocrinol Metab 2010;299:E968-975.

11. Kandadi MR, Hua Y, Zhu M, Turdi S, Nathanielsz PW, Ford SP, Nair S, Ren J. Influence of gestational overfeeding on myocardial proinflammatory mediators in fetal sheep heart. I Nutr Biochem 2013;24:1982-1990.

12. Wang J, Ma H, Tong C, Zhang H, Lawlis GB, Li Y, Zang M, Ren J, Nijland MJ, Ford SP, Nathanielsz PW, Li J. Overnutrition and maternal obesity in sheep pregnancy alter the JNK-IRS-1 signaling cascades and cardiac function in the fetal heart. Faseb j 2010;24:2066-2076.

13. Rosario FJ, Kanai Y, Powell TL, Jansson T. Increased placental nutrient transport in a novel mouse model of maternal obesity with fetal overgrowth. Obesity 2015;23:1663-1670.

14. Acosta O, Ramirez VI, Lager S, Gaccioli F, Dudley DJ, Powell TL, Jansson T. Increased glucose and placental GLUT-1 in large infants of obese nondiabetic mothers. Am J Obstet Gynecol 2015;212:227.e221-227.

15. Powell TL, Barner K, Madi L, Armstrong M, Manke J, Uhlson C, Jansson T, Ferchaud-Roucher V. Sex-specific responses in placental fatty acid oxidation, esterification and transfer capacity to maternal obesity. Biochim Biophys Acta Mol Cell Biol Lipids 2021;1866:158861. 
16. Gázquez A, Prieto-Sánchez MT, Blanco-Carnero JE, Ruíz-Palacios M, Nieto A, van Harskamp D, Oosterink JE, Schierbeek H, van Goudoever JB, Demmelmair H, Koletzko B, Larqué E. Altered materno-fetal transfer of 13C-polyunsaturated fatty acids in obese pregnant women. Clin Nutr 2020;39:1101-1107.

17. Mdaki KS, Larsen TD, Wachal AL, Schimelpfenig MD, Weaver L, Dooyema SD, Louwagie EJ, Baack ML. Maternal high-fat diet impairs cardiac function in offspring of diabetic pregnancy through metabolic stress and mitochondrial dysfunction. 2016;310:H681-692.

18. Turdi S, Ge W, Hu N, Bradley KM, Wang X, Ren J. Interaction between maternal and postnatal high fat diet leads to a greater risk of myocardial dysfunction in offspring via enhanced lipotoxicity, IRS1 serine phosphorylation and mitochondrial defects. Journal of Molecular and Cellular Cardiology 2013;55:117-129.

19. Rijzewijk LJ, van der Meer RW, Lamb HJ, de Jong HW, Lubberink M, Romijn JA, Bax JJ, de Roos A, Twisk JW, Heine RJ, Lammertsma AA, Smit JW, Diamant M. Altered myocardial substrate metabolism and decreased diastolic function in nonischemic human diabetic cardiomyopathy: studies with cardiac positron emission tomography and magnetic resonance imaging. Journal of the American College of Cardiology 2009;54:1524-1532.

20. Herrero P, Peterson LR, McGill JB, Matthew S, Lesniak D, Dence C, Gropler RJ. Increased myocardial fatty acid metabolism in patients with type 1 diabetes mellitus. Journal of the American College of Cardiology 2006;47:598-604.

21. Son N-H, Park T-S, Yamashita H, Yokoyama M, Huggins LA, Okajima K, Homma S, Szabolcs MJ, Huang L-S, Goldberg IJ. Cardiomyocyte expression of PPARY leads to cardiac dysfunction in mice. The Journal of Clinical Investigation 2007;117:2791-2801.

22. Aye IL, Rosario FJ, Powell TL, Jansson T. Adiponectin supplementation in pregnant mice prevents the adverse effects of maternal obesity on placental function and fetal growth. Proc Natl Acad Sci U S A 2015;112:12858-12863.

23. Vaughan OR, Rosario FJ, Powell TL, Jansson T. Normalisation of circulating adiponectin levels in obese pregnant mice prevents cardiac dysfunction in adult offspring. International journal of obesity (2005) 2019.

24. Haberland M, Montgomery RL, Olson EN. The many roles of histone deacetylases in development and physiology: implications for disease and therapy. Nature Reviews Genetics 2009;10:32.

25. Alrob OA, Sankaralingam S, Ma C, Wagg CS, Fillmore N, Jaswal JS, Sack MN, Lehner R, Gupta MP, Michelakis ED, Padwal RS, Johnstone DE, Sharma AM, Lopaschuk GD. Obesity-induced lysine acetylation increases cardiac fatty acid oxidation and impairs insulin signalling. Cardiovasc Res 2014;103:485-497.

26. Hacker A, Capel B, Goodfellow P, Lovell-Badge R. Expression of Sry, the mouse sex determining gene. Development 1995;121:1603-1614.

27. Zheng X, Wen L, Yu S-J, Huang S-C, Feng DD. A study of non-invasive Patlak quantification for whole-body dynamic FDG-PET studies of mice. Biomed Signal Process Control 2012;7:438-446.

28. Kuznetsov AV, Veksler V, Gellerich FN, Saks V, Margreiter R, Kunz WS. Analysis of mitochondrial function in situ in permeabilized muscle fibers, tissues and cells. Nat Protoc 2008;3:965-976.

29. Son NH, Basu D, Samovski D, Pietka TA, Peche VS, Willecke F, Fang X, Yu SQ, Scerbo D, Chang HR, Sun F, Bagdasarov S, Drosatos K, Yeh ST, Mullick AE, Shoghi KI, Gumaste N, Kim K, Huggins LA, Lhakhang T, Abumrad NA, Goldberg IJ. Endothelial cell CD36 optimizes tissue fatty acid uptake. J Clin Invest 2018;128:4329-4342.

30. Suter MA, Chen A, Burdine MS, Choudhury M, Harris RA, Lane RH, Friedman JE, Grove KL, Tackett AJ, Aagaard KM. A maternal high-fat diet modulates fetal SIRT1 histone and protein deacetylase activity in nonhuman primates. The FASEB Journal 2012;26:5106-5114. 
31. McCurdy CE, Schenk S, Hetrick B, Houck J, Drew BG, Kaye S, Lashbrook M, Bergman BC, Takahashi DL, Dean TA, Nemkov T, Gertsman I, Hansen KC, Philp A, Hevener AL, Chicco AJ, Aagaard KM, Grove KL, Friedman JE. Maternal obesity reduces oxidative capacity in fetal skeletal muscle of Japanese macaques. JCl insight 2016;1:e86612.

32. Vidal-Puig A, Jimenez-Liñan M, Lowell BB, Hamann A, Hu E, Spiegelman B, Flier JS, Moller DE. Regulation of PPAR gamma gene expression by nutrition and obesity in rodents. The Journal of clinical investigation 1996;97:2553-2561.

33. Diaz P, Harris J, Rosario FJ, Powell TL, Jansson T. Increased placental fatty acid transporter 6 and binding protein 3 expression and fetal liver lipid accumulation in a mouse model of obesity in pregnancy. Am J Physiol Regul Integr Comp Physiol 2015;309:R1569-1577.

34. Vaduganathan M, Patel RB, Michel A, Shah SJ, Senni M, Gheorghiade M, Butler J. Mode of Death in Heart Failure With Preserved Ejection Fraction. Journal of the American College of Cardiology 2017;69:556-569.

35. Wang YC, Xiao XL, Li N, Yang D, Xing Y, Huo R, Liu MY, Zhang YQ, Dong DL. Oestrogen inhibits BMP4-induced BMP4 expression in cardiomyocytes: a potential mechanism of oestrogenmediated protection against cardiac hypertrophy. British Journal of Pharmacology 2015;172:5586-5595.

36. Nelson JF, Felicio LS, Osterburg HH, Finch CE. Altered profiles of estradiol and progesterone associated with prolonged estrous cycles and persistent vaginal cornification in aging C57BL/6J mice. Biol Reprod 1981;24:784-794.

37. Nelson JF, Felicio LS, Randall PK, Sims C, Finch CE. A longitudinal study of estrous cyclicity in aging C57BL/6J mice: I. Cycle frequency, length and vaginal cytology. Biol Reprod 1982;27:327-339.

38. Ho KKL, Pinsky JL, Kannel WB, Levy D. The epidemiology of heart failure: The Framingham Study. Journal of the American College of Cardiology 1993;22:A6-A13.

39. Kadkhodayan A, Lin CH, Coggan AR, Kisrieva-Ware Z, Schechtman KB, Novak E, Joseph SM, DavilaRoman VG, Gropler RJ, Dence C, Peterson LR. Sex affects myocardial blood flow and fatty acid substrate metabolism in humans with nonischemic heart failure. Journal of nuclear cardiology: official publication of the American Society of Nuclear Cardiology 2017;24:1226-1235.

40. Peterson LR, Soto PF, Herrero P, Schechtman KB, Dence C, Gropler RJ. Sex Differences in Myocardial Oxygen and Glucose Metabolism. Journal of nuclear cardiology : official publication of the American Society of Nuclear Cardiology 2007;14:573-581.

41. Iozzo P, Chareonthaitawee P, Dutka D, Betteridge DJ, Ferrannini E, Camici PG. Independent association of type 2 diabetes and coronary artery disease with myocardial insulin resistance. Diabetes 2002;51:3020-3024.

42. Cole MA, Murray AJ, Cochlin LE, Heather LC, McAleese S, Knight NS, Sutton E, Jamil AA, Parassol $\mathrm{N}$, Clarke K. A high fat diet increases mitochondrial fatty acid oxidation and uncoupling to decrease efficiency in rat heart. Basic research in cardiology 2011;106:447-457.

43. Guzzardi MA, Liistro T, Gargani L, Ait Ali L, D'Angelo G, Rocchiccioli S, La Rosa F, Kemeny A, Sanguinetti E, Ucciferri N, De Simone M, Bartoli A, Festa P, Salvadori PA, Burchielli S, Sicari R, lozzo P. Maternal Obesity and Cardiac Development in the Offspring: Study in Human Neonates and Minipigs. JACC Cardiovasc Imaging 2018;11:1750-1755.

44. Mikkelsen TS, Xu Z, Zhang X, Wang L, Gimble JM, Lander ES, Rosen ED. Comparative epigenomic analysis of murine and human adipogenesis. Cell 2010;143:156-169.

45. Aagaard-Tillery KM, Grove K, Bishop J, Ke X, Fu Q, McKnight R, Lane RH. Developmental origins of disease and determinants of chromatin structure: maternal diet modifies the primate fetal epigenome. Journal of Molecular Endocrinology 2008;41:91-102.

46. Robinson MD, Oshlack A. A scaling normalization method for differential expression analysis of RNA-seq data. Genome Biology 2010;11:R25. 
47. Benjamini Y, Hochberg Y. Controlling the False Discovery Rate: A Practical and Powerful Approach to Multiple Testing. Journal of the Royal Statistical Society: Series B (Methodological) 1995;57:289300.

48. Ferchaud-Roucher V, Rudolph MC, Jansson T, Powell TL. Fatty acid and lipid profiles in primary human trophoblast over $90 \mathrm{~h}$ in culture. Prostaglandins, leukotrienes, and essential fatty acids

591 2017;121:14-20.

592

49. Matyash V, Liebisch G, Kurzchalia TV, Shevchenko A, Schwudke D. Lipid extraction by methyl-tert-

\section{3}

594
50. Harrison KA, Bergman BC. HPLC-MS/MS Methods for Diacylglycerol and Sphingolipid Molecular Species in Skeletal Muscle. Methods Mol Biol 2019;1978:137-152.


597 Table 1 Effect of maternal obesity on body and heart weights in E18.5 fetuses

\begin{tabular}{|l|l|l|l|}
\hline & Con & Ob & P value (t test) \\
\hline Males & $\mathrm{n}=5$ litters & $\mathrm{n}=5$ litters & \\
\hline Body weight $(\mathrm{g})$ & $1050 \pm 50$ & $1272 \pm 26$ & $\mathbf{0 . 0 0 4 ^ { * }}$ \\
\hline Heart weight $(\mathrm{mg})$ & $4.84 \pm 0.56$ & $7.64 \pm 0.28$ & $\mathbf{0 . 0 0 2}$ \\
\hline & & & \\
\hline Females & $\mathrm{n}=5$ litters & $\mathrm{n}=5$ litters & \\
\hline Body weight (g) & $995 \pm 43$ & $1228 \pm 58$ & $\mathbf{0 . 0 1 2}$ \\
\hline Heart weight (mg) & $3.88 \pm 0.26$ & $7.14 \pm 0.32$ & $<\mathbf{0 . 0 0 1}$ \\
\hline & & & \\
\hline
\end{tabular}

599 Body and heart weights, determined at necropsy, in male and female fetuses of control (Con) and obese 600 (Ob) dams. Litter mean values for Con and Ob groups compared by Student's t-test. *, P<0.05. Mean \pm 601 SEM.

602 
Table 2 Effect of maternal obesity on body and heart weights in 6-month-old adult offspring

\begin{tabular}{|l|l|l|l|}
\hline & Con & Ob & P value (t test) \\
\hline Males & $\mathrm{n}=47$ & $\mathrm{n}=31$ & \\
\hline Body weight $(\mathrm{g})$ & $36.4 \pm 0.9$ & $36.1 \pm 1.1$ & 0.830 \\
\hline Heart weight $(\mathrm{mg})$ & $158 \pm 3$ & $162 \pm 5$ & 0.527 \\
\hline (\% body wt. $\times$ 1000) & $4.40 \pm 0.10$ & $4.55 \pm 0.16$ & 0.405 \\
\hline LV weight (g) & $112 \pm 2$ & $114 \pm 4$ & 0.623 \\
\hline (\% body wt. $\times$ 1000) & $3.08 \pm 0.07$ & $3.24 \pm 0.16$ & 0.289 \\
\hline & & & \\
\hline Females & $\mathrm{n}=42$ & $\mathrm{n}=34$ & \\
\hline Body weight $(\mathrm{g})$ & $26.8 \pm 0.7$ & $28.5 \pm 0.9$ & 0.149 \\
\hline Heart weight $(\mathrm{mg})$ & $127 \pm 3$ & $139 \pm 4$ & $0.012 *$ \\
\hline (\% body wt. $\times 1000)$ & $4.79 \pm 0.10$ & $4.97 \pm 0.16$ & 0.305 \\
\hline LV weight $(\mathrm{g})$ & $89.7 \pm 2.4$ & $93.9 \pm 3.54$ & 0.325 \\
\hline (\% body wt. $\times$ 1000) & $3.35 \pm 0.06$ & $3.44 \pm 0.13$ & 0.561 \\
\hline & & & \\
\hline
\end{tabular}

604

605 Body, heart and LV weight, determined at necropsy, in 6-month old male and female offspring of control

606 (Con) and obese (Ob) dams. Con and Ob groups compared by Student's t-test. *, $\mathrm{P}<0.05$. Mean \pm SEM. 
Table 3 Effect of maternal obesity on cardiac fatty acid and glucose transporter expression in 6month-old adult offspring

\begin{tabular}{|l|l|l|l|}
\hline & Con & Ob & P value (t test) \\
\hline Males & $\mathrm{n}=10$ & $\mathrm{n}=10$ & \\
\hline CD36 & $1.00 \pm 0.05$ & $1.02 \pm 0.06$ & 0.748 \\
\hline FATP1 & $1.00 \pm 0.23$ & $0.90 \pm 0.32$ & $0.331^{\mathrm{b}}$ \\
\hline FATP6 & $1.00 \pm 0.24$ & $1.25 \pm 0.28$ & 0.501 \\
\hline GLUT1 & $1.00 \pm 0.10$ & $1.18 \pm 0.15$ & 0.321 \\
\hline GLUT4 & $1.00 \pm 0.12$ & $1.12 \pm 0.11$ & 0.448 \\
\hline & & & \\
\hline Females & $\mathrm{n}=10$ & $\mathrm{n}=10$ & \\
\hline CD36 & $1.00 \pm 0.05$ & $0.95 \pm 0.06$ & 0.462 \\
\hline FATP1 & $1.00 \pm 0.18$ & $2.27 \pm 0.67$ & $0.143^{\mathrm{a}}$ \\
\hline FATP6 & $1.00 \pm 0.17$ & $0.44 \pm 0.06$ & $\mathbf{0 . 0 0 6} \mathbf{b}^{\mathrm{b}}$ \\
\hline GLUT1 & $1.00 \pm 0.32$ & $0.88 \pm 0.34$ & $0.310^{\mathrm{a}}$ \\
\hline GLUT4 & $1.00 \pm 0.03$ & $1.02 \pm 0.05$ & 0.746 \\
\hline & & & \\
\hline
\end{tabular}

609

610 Relative transporter protein abundance in LV homogenates, determined by western blot, in 6-month old

611 male and female offspring of control (Con) and obese (Ob) dams. Con and Ob groups compared by

612 Student's t-test or Mann-Whitney test ${ }^{a}$, as appropriate to distribution. ${ }^{b}$ Log transformed prior to

613 statistical analysis. ${ }^{*} \mathrm{P}<0.05$. Mean \pm SEM. 
Fig. 1 Maternal obesity induces fetal cardiac hypertrophy in association with altered transcription of metabolic genes at E18.5.

618 (A, B) Heart weight, relative to body weight, in female and male fetuses of control (Con) and obese (Ob) dams, on E18.5 of gestation. Con and Ob groups compared by Student's t-test. $\mathrm{P}$ and $\mathrm{n}$ values given in figure. Bars are mean \pm SEM. Symbols represent mean values of all pups of each sex within one litter. (C

621 - F) Top 10 biological processes, ranked by $P$ value, predicted to be inhibited (C, D) or activated (E, F) in

622 hearts of female and male fetuses of obese dams, based on Ingenuity Pathway Analysis of differential gene expression, compared to controls. Activation status determined by z-score $>|1.7|$. (G) Comparison

624 of biological processes activated or inhibited in response to maternal obesity, in male and female fetuses.

625 Color scale indicates activation z-score relative to control fetuses. $(\mathrm{H})$ Comparison of metabolic genes 626 differentially expressed in response to maternal obesity, in male and female fetuses. Color scale indicates

627 differential expression relative to control fetuses. (I, J) Predicted effect of differentially expressed metabolic genes on downstream biological processes in hearts of female and male fetuses of obese dams.

629 Color of molecules represents expression change Ob vs Con: red, upregulated; green, downregulated.

630 Color of arrows represents direction of predicted effect on downstream processes: orange, activation; 631 grey, neutral; yellow, expression inconsistent with predicted activation. (K, L) Least-squared mean relative PPARG expression in female and male fetal hearts from Con and Ob dams determined by RNASeq ( $n=5$ of each sex per group). $P$ values given in figure.

Fig. 2 Maternal obesity causes age- and sex-dependent left ventricular diastolic dysfunction in adult offspring.

636

Echocardiographic indices of diastolic function in 3- to 24-month old male (A, C, E) and female (B, D, F) offspring of control (white bars) and obese dams (grey bars). (A, B) Ratios of early- to late-diastolic left ventricular wall displacement determined by tissue Doppler ( $\left.E^{\prime} / A^{\prime}\right)$. (C, D) Ratios of early- to late-diastolic mitral inflow determined by pulsed wave Doppler (E/A). (E, F) Ratio of early diastolic mitral inflow to wall displacement $\left(E / E^{\prime}\right)$. Main effects of maternal obesity and postnatal age, and their interaction, were determined by two-way ANOVA and P values given in figure. Post-hoc comparisons of Con and Ob groups at each age used the Sidak test; ${ }^{*} \mathrm{P}<0.05,{ }^{* *} \mathrm{P}<0.01,{ }^{* *} \mathrm{P}<0.001$. Bars are mean $\pm \mathrm{SEM}$. Symbols represent individual animals. $\mathrm{n}$ values given in bars.

\section{Fig. 3 Maternal obesity causes age- and sex-dependent left ventricular dilatation in adult offspring.}


645

646

647

648

649

650

651

652

653

654

655

656

657

658

659

660

661

662

663

664

665

666

667

668

669

670

671

672

673

674

Left ventricular end-diastolic and end-systolic volumes, determined by echocardiography, in 3- to 24month old male (A, C) and female (B, D) offspring of control (white bars) and obese dams (grey bars). Main effects of maternal obesity and postnatal age, and their interaction, were determined by two-way ANOVA and $\mathrm{P}$ values given in figure. Post-hoc comparisons of Con and Ob groups at each age used the Sidak test; $* \mathrm{P}<0.05,{ }^{* *} \mathrm{P}<0.01, * * * \mathrm{P}<0.001$ Bars are mean $\pm \mathrm{SEM}$. Points represent individual animals. $\mathrm{n}$ values given in figure.

Fig. 4 Maternal obesity increases cardiac expression of Pparg and its downstream targets in adult offspring.

Relative expression of candidate genes in left ventricles of 6 -month old old male ( $A$, Con $n=11, O b n=10)$ and female $(B$, Con $n=9, O b n=10)$ offspring at age 6 months, determined by qPCR relative to Rna18s and Rps29. Bars are mean \pm SEM. Con and Ob offspring compared by Student's t-test.*, P<0.05. (C, D) Correlation of left ventricular Pparg expression with E/E' ratio in male offspring and end-diastolic volume in female offspring of Con and Ob dams. Relationship between variables assessed by Pearson's correlation, $\mathrm{P}, \mathrm{R}$ and $\mathrm{N}$ values given in figure. Least-squares regression line shown.

Fig. 5 Maternal obesity increases myocardial fatty acid oxidation in adult male, but not female, offspring (A, B) In vivo left ventricular $3 \mathrm{H}$-oleic acid clearance in male (Con $n=7, O b n=4$ ) and female (Con $n=3, O b$ $\mathrm{n}=6$ ) offspring. (C, D) Palmitoyl carnitine-supported mitochondrial respiration rates in isolated, permeabilized cardiac myofibers from 6-month old male (Con $n=16, O b n=10$ ) and female (Con $n=16, O b$ $\mathrm{n}=9$ ) offspring of Con and Ob dams. Respiration rates and clearances compared between Con and Ob groups by Student's t-test, $P$ values given in figure. Mean \pm SEM. Symbols represent individual offspring. (E) Correlation between palmitoyl carnitine supported coupling control ratio and Pparg expression in male offspring. Relationship between variables determined by Pearson's correlation, $\mathrm{P}$ and $\mathrm{R}$ values in figure. Least-squares regression line shown.

Fig. 6 Maternal obesity impairs myocardial glucose uptake in adult female, but not male, offspring

(A-D) Left ventricular 8F-fluorodeoxyglucose clearance in male (Con $n=8, O b n=9$ ) and female (Con $n=10$, Ob $n=11$ ) offspring of control and obese dams at age 6 months. Con and Ob groups compared by leastsquare linear regression of $(A, C)$ Patlak plot, symbols represent mean \pm SEM values for all individuals within each group, at each normalized time point. (B, D) Histogram of mean \pm SEM clearance (gradient of Patlak plot) for each experimental group. (E, F) Pyruvate-supported mitochondrial respiration rates in isolated, permeabilized cardiac myofibers from 6-month old male (Con $n=16,0 b n=10$ ) and female (Con 
$675 n=15, O b n=9)$ offspring of control and obese dams. Con and Ob groups compared by Student's t test. P 676 values for intergroup comparisons given in figure. Bars are mean + SEM. Points represent individual 677 animals.

678 Fig. 7 Maternal obesity does not affect myocardial histone H3 acetylation in adult offspring.

679 Relative protein abundance of total (A, B), acetyl-lysine-27 (C, D) and acetyl-lysine-9 (E, F) histone H3 in 680 6-month old male and female offspring of Con and Ob dams. Con and Ob groups compared by Student's 681 t-test, $\mathrm{P}$ values given in figure. Bars are mean \pm SEM. Points represent individual animals. $\mathrm{n}$ values given 682 in figure. 


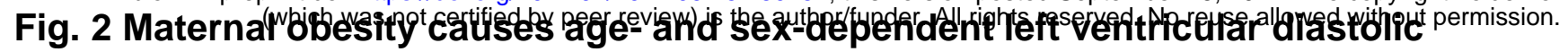
dysfunction in adult offspring. $\bigcirc$ Control $\square$ Obese
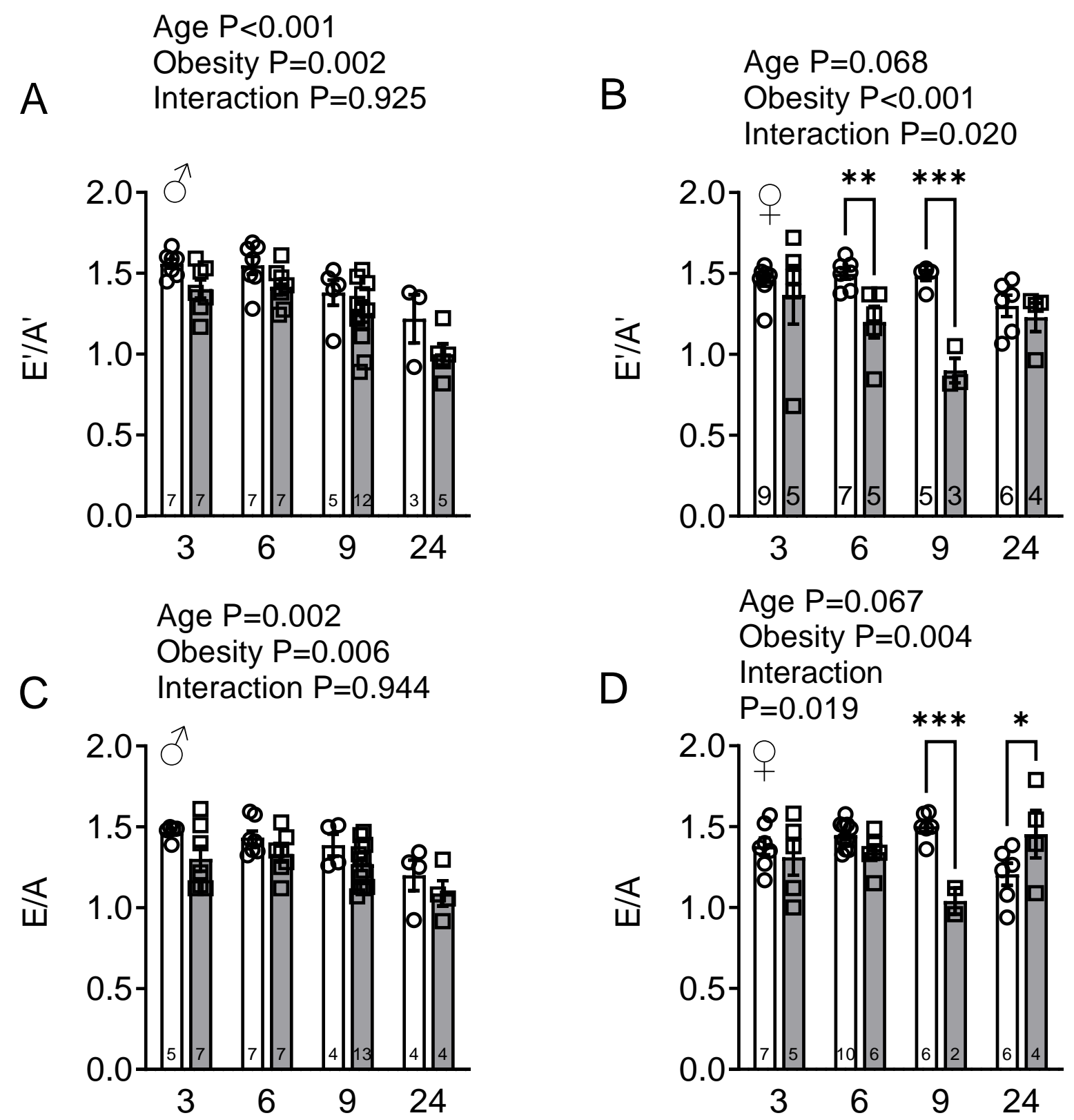

Age $P=0.067$

Obesity $P=0.004$

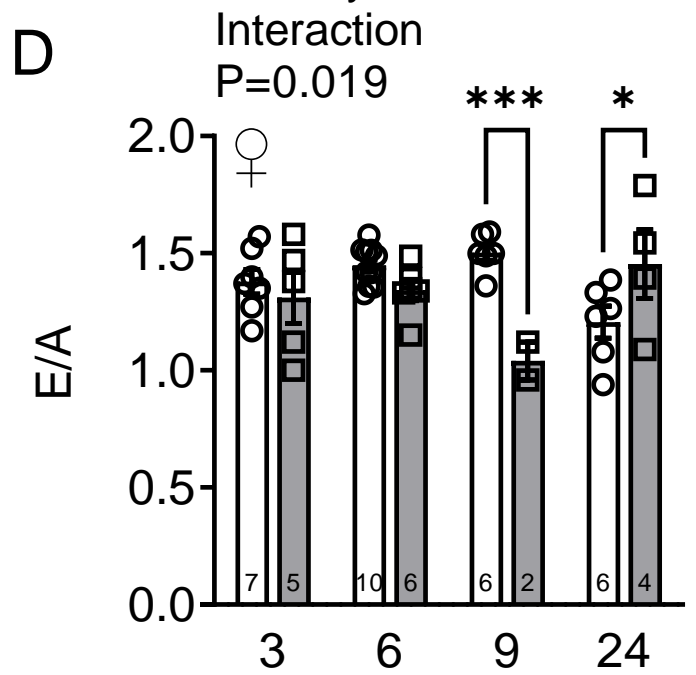

Age $\mathrm{P}<0.001$

Obesity $P<0.001$

Interaction $\mathrm{P}=0.001$

E

****

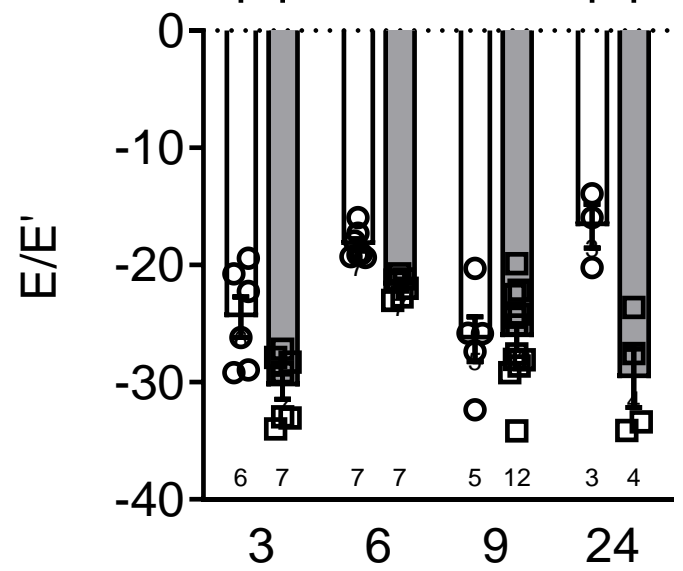

Age $\mathrm{P}=0.115$

Obesity $P=0.002$

Interaction $\mathrm{P}=0.578$

F $\quad$ q

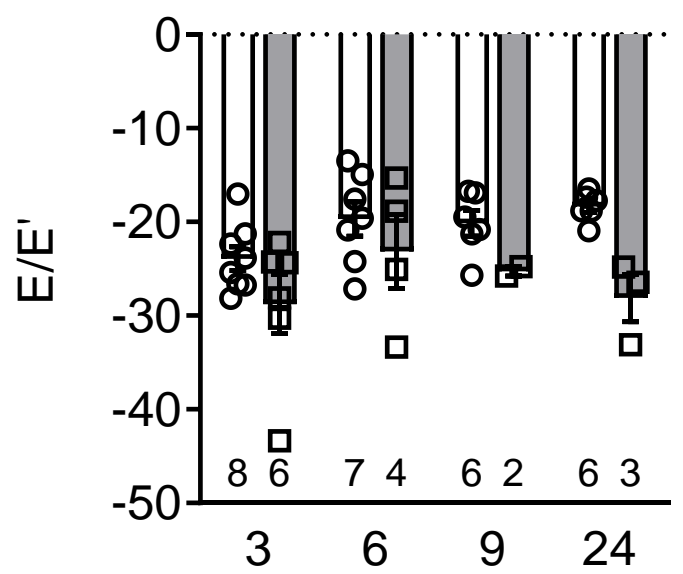




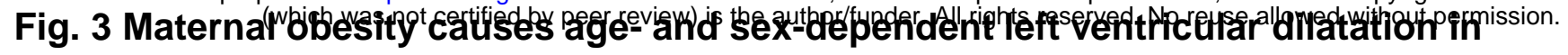
adult offspring.

A Age $P=0.021$

Obesity $P=0.012$

Interaction $\mathrm{P}=0.003$

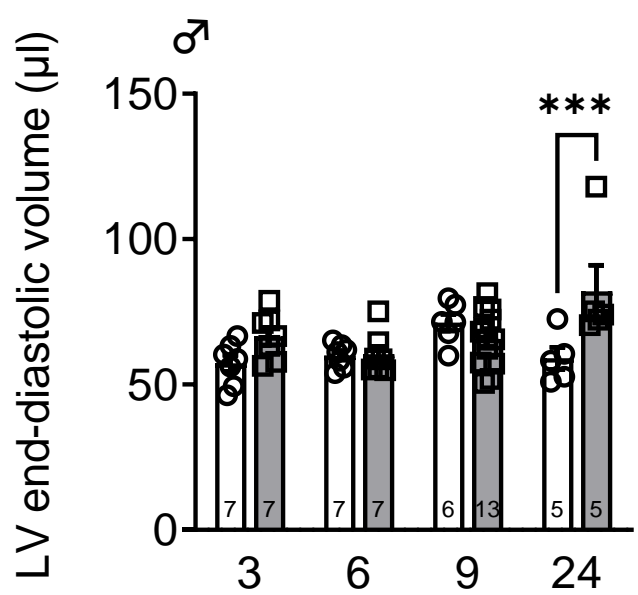

C Age $\mathrm{P}=0.911$

Interaction $\mathrm{P}=0.288$

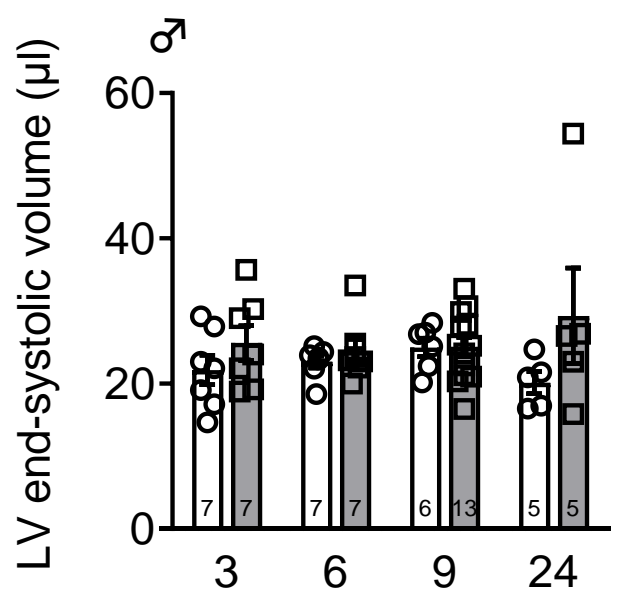

B Age $P<0.001$

Obesity $P=0.038$

Interaction $\mathrm{P}=0.548$

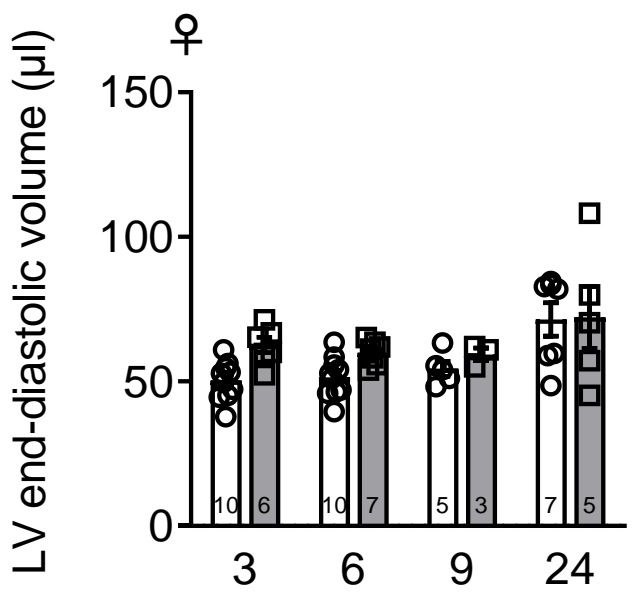

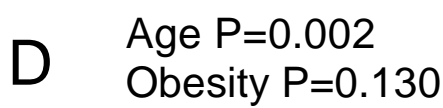
Interaction $\mathrm{P}=0.818$

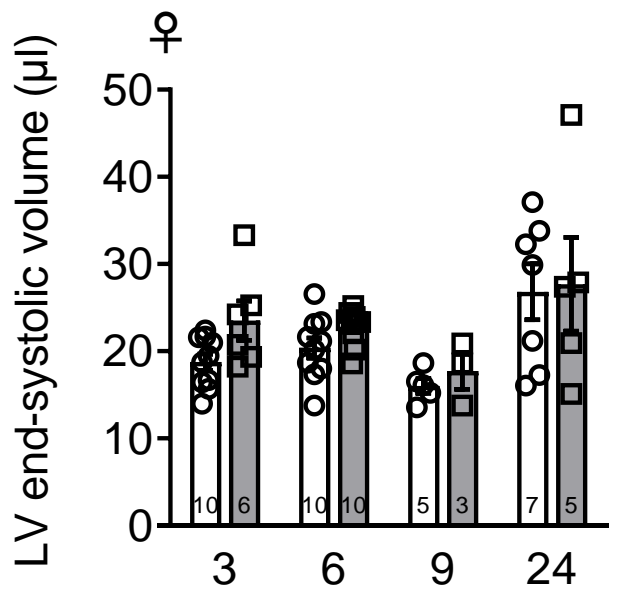


Fig. 4 Maternal obesity increases cardiac expression of Pparg and its downstream targets in adult offspring.

A

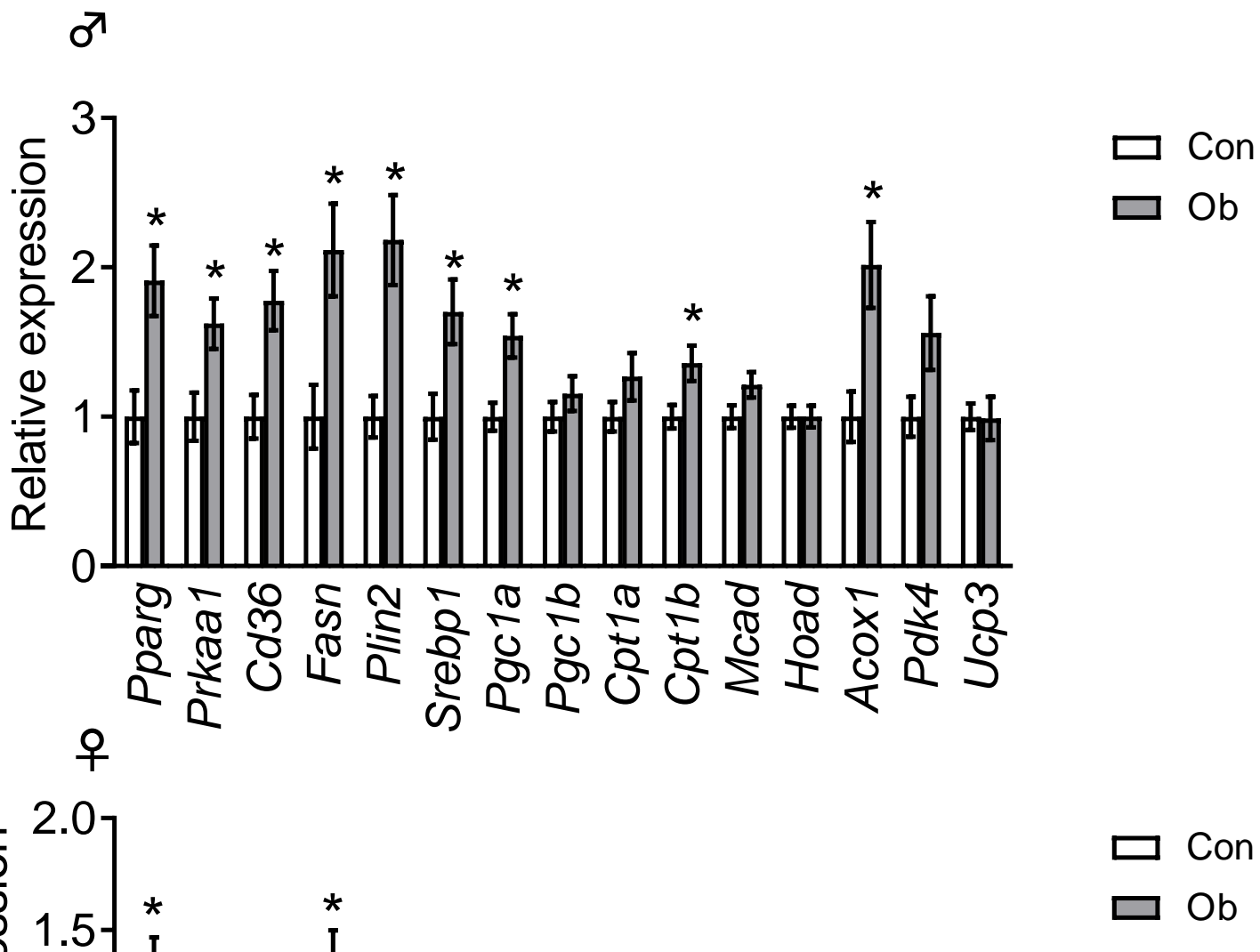

C

\section{B}
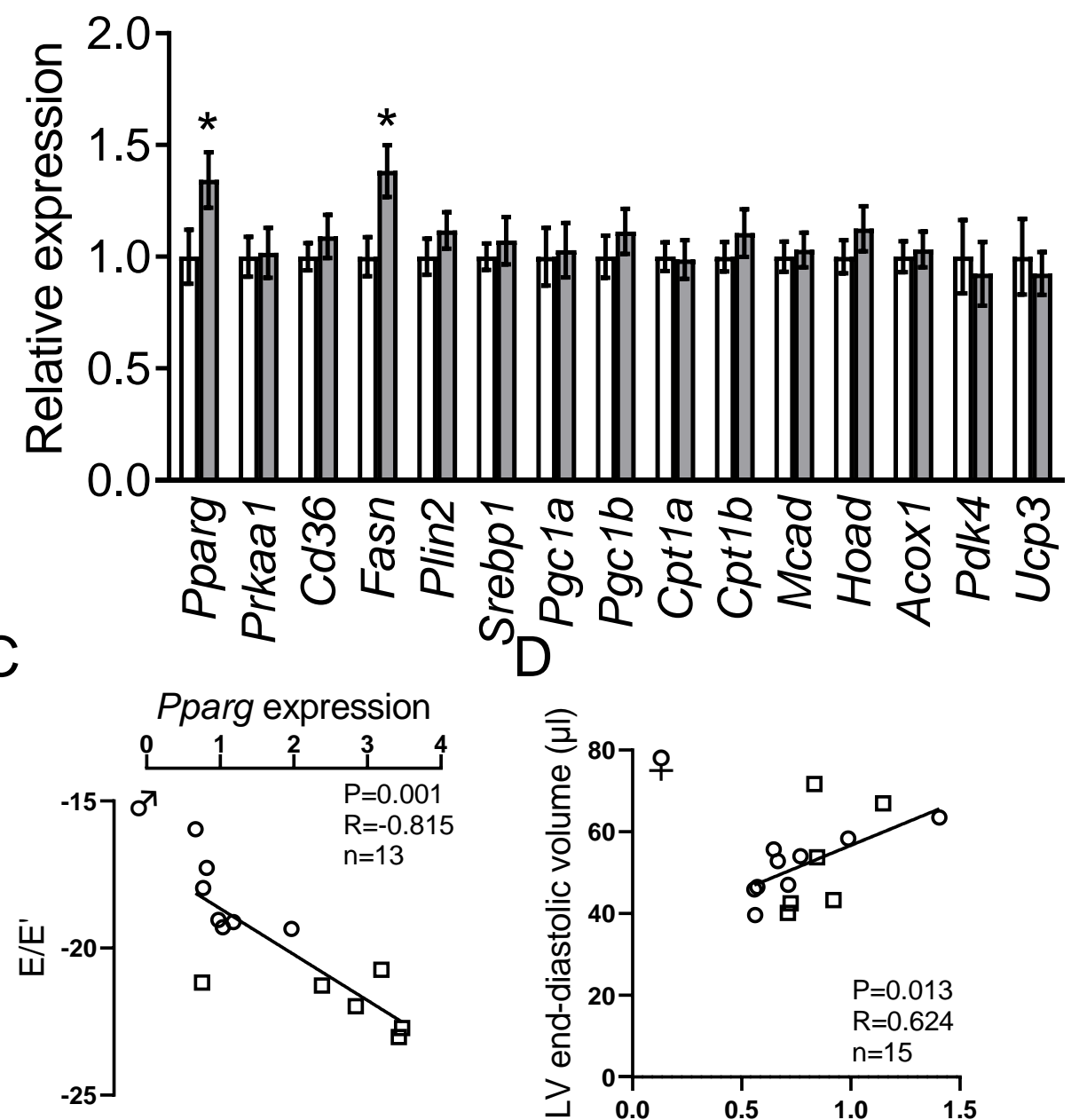

- Con a Ob

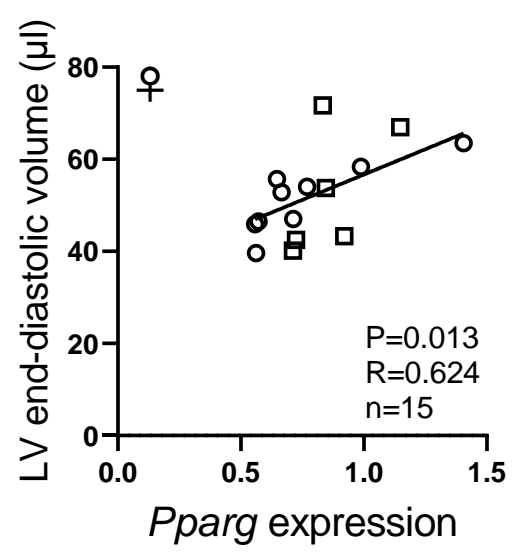


Fig. 5 Maternal obesity increases myocardial fatty acid oxidation in adult male, but not female, offspring

A

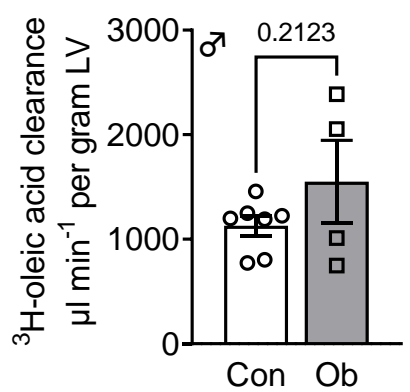

B

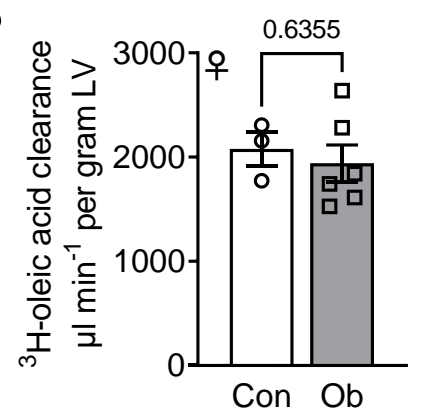

C

Palmitoyl carnitine-supported D

Palmitoyl carnitine-supported E
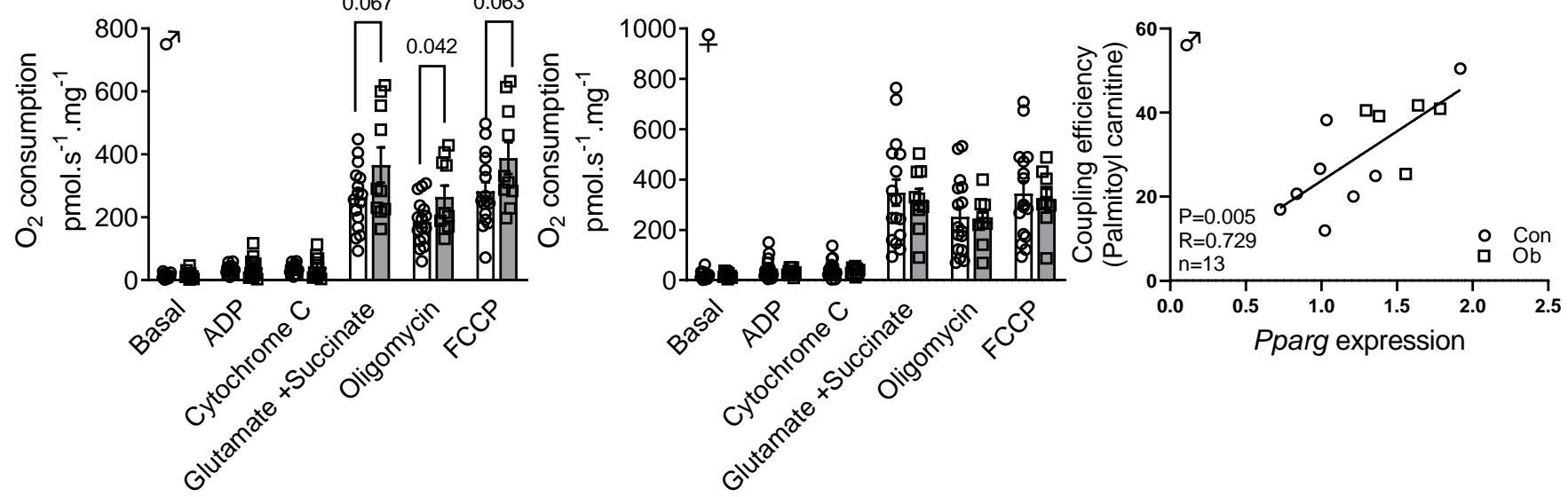
Fig. 6 Maternal obesity impairs myocardial glucose uptake in adult female, but not male, offspring

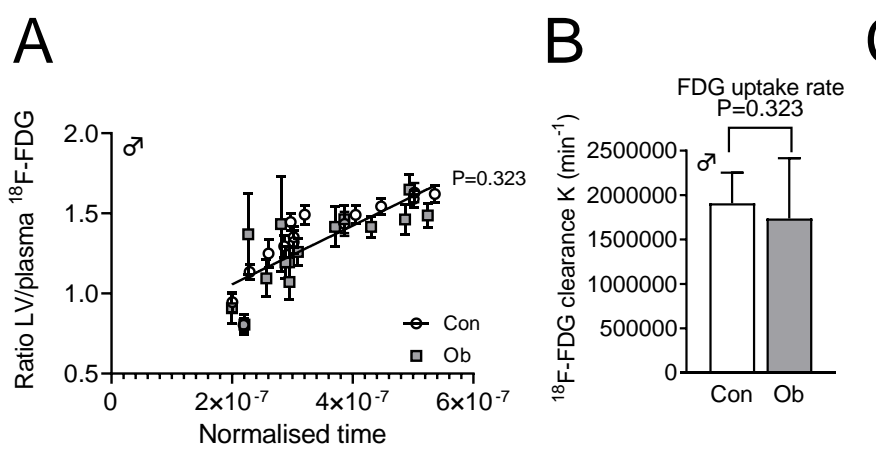

C
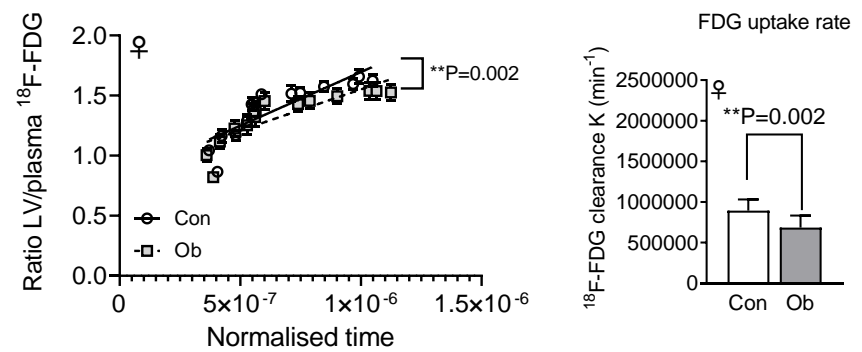

$E$

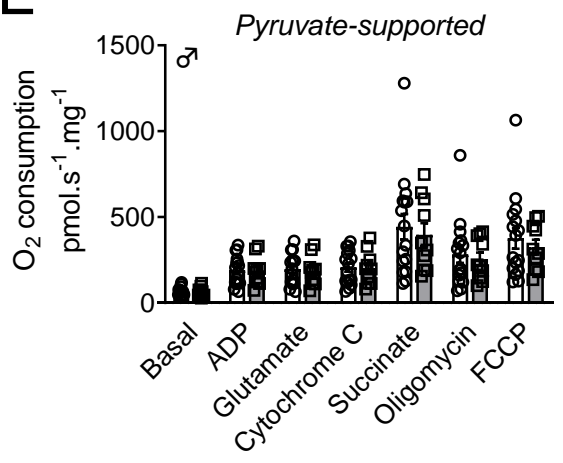

$\mathrm{F}$

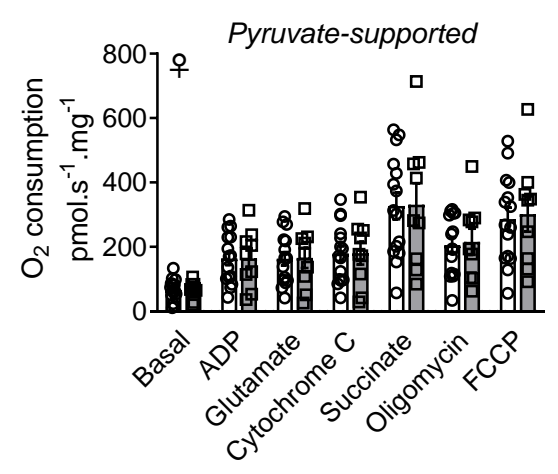


Fig. 7 Maternal obesity does not affect myocardial histone $\mathrm{H} 3$ acetylation in adult offspring.

A Histone $\mathrm{H} 3$

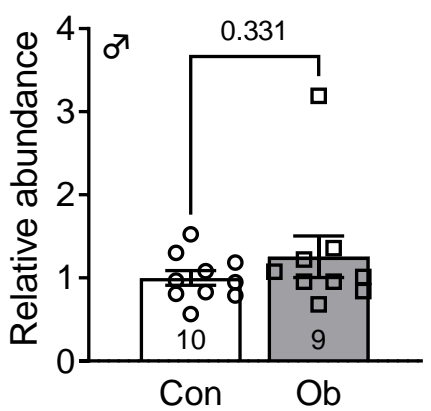

C

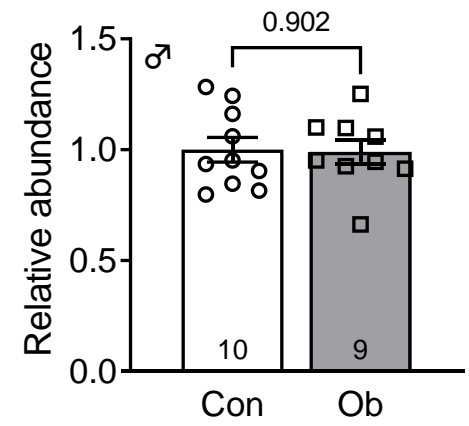

$\mathrm{E}$

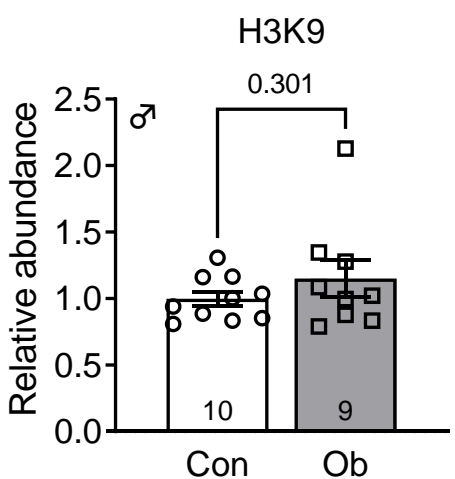

B Histone $\mathrm{H} 3$

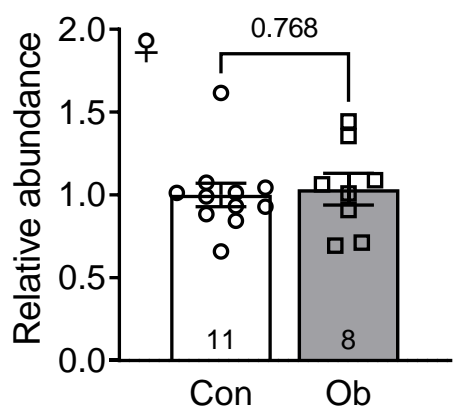

D $\quad$ H3K27

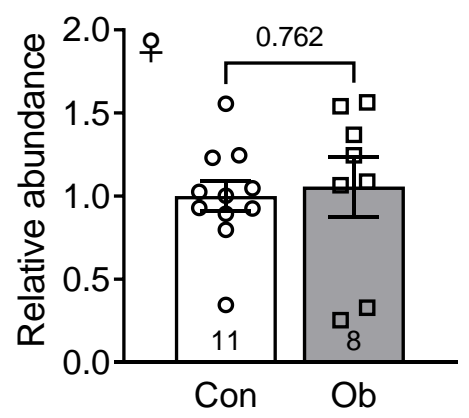

$\mathrm{F}$ H3K9

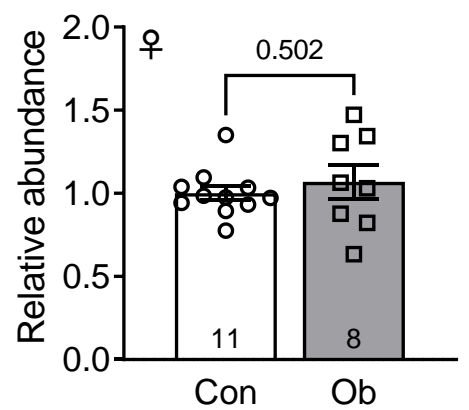


3 MATERNAL OBESITY CAUSES FETAL CARDIAC HYPERTROPHY AND ALTERS ADULT OFFSPRING 4 MYOCARDIAL METABOLISM IN MICE

6 Owen R. Vaughan ${ }^{1}$, Fredrick J. Rosario ${ }^{1}$, Jeannie Chan ${ }^{2}$, Laura A. Cox ${ }^{2}$, Veronique Ferchaud-Roucher ${ }^{1}$, Karin

7 A. Zemski-Berry ${ }^{3}$, Jane E.B. Reusch ${ }^{3}$, Amy C. Keller ${ }^{3}$, Theresa L. Powell ${ }^{1,4}$ and Thomas Jansson ${ }^{1}$

$8{ }^{1}$ Department of Obstetrics and Gynecology, University of Colorado Anschutz Medical Campus, Aurora, CO, 9 USA

$10{ }^{2}$ Department of Molecular Medicine, Wake Forest School of Medicine, Winston-Salem, NC, USA

$11{ }^{3}$ Department of Medicine, Division of Endocrinology, Metabolism and Diabetes, University of Colorado

12 Anschutz Medical Campus, Aurora, CO, USA and Rocky Mountain Regional VA Medical Center, Aurora, CO,

13 USA

$14{ }^{4}$ Department of Pediatrics, University of Colorado Anschutz Medical Campus, Aurora, CO, USA

15

Short title: Maternal obesity alters offspring heart metabolism

17 Manuscript category: Original article

18 Correspondence:

19 Owen R. Vaughan, PhD

20 Department of Obstetrics and Gynecology

21 University of Colorado Anschutz Medical Campus

2212700 E19th Avenue

23 Aurora, CO, USA

24 owen.vaughan@CUAnschutz.edu

25 Phone: (303) 724-8622

26 Fax: (303) 724-3512 


\section{SUPPLEMENTARY TABLES}

28 Suppl. Table 1 Primer sequences used for qRT- PCR analysis of adult offspring hearts

\begin{tabular}{|l|l|l|l|}
\hline Target mRNA & Forward primer sequence & Reverse primer sequence & Source reference \\
\hline Pparg & GAGTGTGACGACAAGATTTG & GGTGGGCCAGAATGGCATCT & PMID: 25157099 \\
\hline Cd36 & AATGGCACAGACGCAGCCT & GGTTGTCTGGATTCTGGA & PMID: 25157099 \\
\hline Prkaa1 & GTCAAAGCCGACCCAATGATA & CGTACACGCAAATAATAGGGGTT & PMID: 31409640 \\
\hline Pgc1a & TGTTCCCGTCACCATATTCC & TCCCGCTTCTCGTGCTCTTT & PMID: 22932259 \\
\hline Pgc1b & AGGTGTTCGGTGAGATTGTA & TCAGATGTGGGATCATAGTCA & PMID: 22932260 \\
\hline Cpt1a & CTCAGTGGGAGCGACTCTTCA & GGCCTCTGTGGTACACGACAA & PMID: 22932258 \\
\hline Cpt1b & TTCAACACTACACGCATCCC & GCCCTCATAGAGCCAGACC & PMID: 22932257 \\
\hline Mcad & GATGCATCACCCTCGTGTAAC & AAGCCCTTTCCCCTGAAG & PMID: 23349477 \\
\hline Hoad & GCAAAATCCAAGAAGGGAATTG & TGGTTGAAAGGCAGCTCAG & PMID: 21990309 \\
\hline Pdk4 & CCGCTGTCCATGAAGCA & GCAGAAAAGCAAAGGACGTT & PMID: 16314495 \\
\hline$U c p 3$ & CCAACATCACAAGAAATGC & TACAAACATCATCACGTTCC & PMID: 12351640 \\
\hline & & & \\
\hline
\end{tabular}

29 
bioRxiv preprint doi: https://doi.org/10.1101/2021.09.15.460457; this version posted September 16, 2021. The copyright holder for this preprint (which was not certified by peer review) is the author/funder. All rights reserved. No reuse allowed without permission.

31 Suppl. Table 3 Effect of maternal obesity on mitochondrial coupling efficiency in adult offspring

\begin{tabular}{|l|l|l|l|}
\hline & Con & Ob & P value (t test) \\
\hline Males & $\mathrm{n}=16$ & $\mathrm{n}=10$ & 0.625 \\
\hline $\begin{array}{l}\text { Palmitoyl-carnitine } \\
\text { supported respiration }\end{array}$ & $33.4 \pm 2.0$ & $31.5 \pm 3.6$ & 0.218 \\
\hline $\begin{array}{l}\text { Pyruvate-supported } \\
\text { respiration }\end{array}$ & $26.8 \pm 7.5$ & $23.2 \pm 6.1$ & 0.475 \\
\hline Females & $\mathrm{n}=15$ & $\mathrm{n}=9$ & 0.871 \\
\hline $\begin{array}{l}\text { Palmitoyl-carnitine } \\
\text { supported respiration }\end{array}$ & $29.0 \pm 1.6$ & $27.0 \pm 2.3$ & \\
\hline $\begin{array}{l}\text { Pyruvate-supported } \\
\text { respiration }\end{array}$ & $28.4 \pm 8.0$ & $28.9 \pm 8.1$ & \\
\hline & & & \\
\hline
\end{tabular}

32 Coupling efficiencies for each of the two combinations of substrates was calculated as 1 minus the 33 ratio (leak state respiration/maximal electron transport chain capacity). 
bioRxiv preprint doi: https://doi.org/10.1101/2021.09.15.460457; this version posted September 16, 2021. The copyright holder for this preprint (which was not certified by peer review) is the author/funder. All rights reserved. No reuse allowed without permission.

Suppl. Table 4. Effect of maternal obesity on adult offspring myocardial fatty acid content.

\begin{tabular}{|c|c|c|c|}
\hline $\mathrm{nmol} / \mathrm{mg}$ protein & Con & Ob & $P$ value (t-test) \\
\hline Males & $\mathrm{n}=10$ & $\mathrm{n}=10$ & \\
\hline $12: 0$ & $17.8 \pm 8.7$ & $6.9 \pm 4.7$ & 0.991 \\
\hline $14: 0$ & $50.1 \pm 28.3$ & $55.0 \pm 31.0$ & 1.000 \\
\hline $16: 0$ & $1983.0 \pm 424.3$ & $1984.0 \pm 432.4$ & 1.000 \\
\hline $16: 1 n-7$ & $16.6 \pm 1.5$ & $17.3 \pm 6.0$ & 1.000 \\
\hline $18: 0$ & $1970.0 \pm 264.7$ & $2025.0 \pm 227.0$ & 1.000 \\
\hline $18: 1 n-9$ & $1095.0 \pm 121.6$ & $1037.0 \pm 189.8$ & 1.000 \\
\hline $18: 2 n-6$ & $4971.0 \pm 615.8$ & $4790.0 \pm 405.0$ & 1.000 \\
\hline $18: 3 n-3$ & $7.3 \pm 0.7$ & $6.6 \pm 0.5$ & 0.999 \\
\hline $18: 3 n-6$ & $0.01 \pm 0.01$ & $0.01 \pm 0.004$ & 1.000 \\
\hline $20: 1 n-9$ & $62.7 \pm 6.3$ & $63.3 \pm 3.4$ & 1.000 \\
\hline $20: 3 n-6$ & $73.2 \pm 6.6$ & $66.9 \pm 3.6$ & 0.999 \\
\hline $20: 4 n-6$ & $1666.0 \pm 148.6$ & $1745.0 \pm 79.8$ & 1.000 \\
\hline $20: 5 n-3$ & $8.9 \pm 10.1$ & $15.5 \pm 12.3$ & 1.000 \\
\hline $22: 4 n-6$ & $81.9 \pm 8.0$ & $59.9 \pm 6.1$ & 0.496 \\
\hline $22: 5 n-3$ & $255.8 \pm 28.5$ & $185.3 \pm 12.4$ & 0.460 \\
\hline $22: 6 n-3$ & $2927.0 \pm 224.4$ & $2547.0 \pm 192.4$ & 0.973 \\
\hline $22: 5 n-6$ & $270.7 \pm 18.8$ & $255.3 \pm 10.2$ & 0.999 \\
\hline Total fatty acids & $15463 \pm 1554$ & $14859 \pm 1288$ & 0.768 \\
\hline Females & $n=10$ & $n=10$ & \\
\hline $12: 0$ & $14.2 \pm 9.1$ & $0.9 \pm 4.1$ & 0.981 \\
\hline $14: 0$ & $91.4 \pm 57.3$ & $3.8 \pm 14.4$ & 0.875 \\
\hline $16: 0$ & $2183.0 \pm 709.7$ & $1064.0 \pm 244.6$ & 0.113 \\
\hline $16: 1 n-7$ & $15.8 \pm 5.1$ & $14.1 \pm 2.6$ & 0.996 \\
\hline $18: 0$ & $2394 \pm 350.3$ & $1817.0 \pm 148.6$ & 0.644 \\
\hline $18: 1 n-9$ & $1181.0 \pm 358.8$ & $746.6 \pm 155.3$ & 0.595 \\
\hline $18: 2 n-6$ & $5859.0 \pm 391.5$ & $5489.0 \pm 423.3$ & 0.195 \\
\hline $18: 3 n-3$ & $9.9 \pm 1.4$ & $8.9 \pm 0.8$ & 0.999 \\
\hline $18: 3 n-6$ & $27.4 \pm 18.1$ & $17.4 \pm 22.7$ & 0.985 \\
\hline $20: 1 n-9$ & $55.7 \pm 6.0$ & $38.8 \pm 3.9$ & 0.982 \\
\hline $20: 3 n-6$ & $54.0 \pm 2.2$ & $48.1 \pm 3.6$ & 1.000 \\
\hline $20: 4 n-6$ & $1936.0 \pm 99.2$ & $1679.0 \pm 87.3$ & 0.998 \\
\hline $20: 5 n-3$ & $20.5 \pm 19.6$ & $-14.7 \pm 9.4$ & 0.929 \\
\hline $22: 4 n-6$ & $68.2 \pm 3.3$ & $65.9 \pm 5.3$ & 0.991 \\
\hline $22: 5 n-3$ & $138.6 \pm 9.9$ & $131.8 \pm 8.5$ & 0.986 \\
\hline $22: 6 n-3$ & $3008.0 \pm 226.9$ & $2732.0 \pm 204.2$ & 0.850 \\
\hline $22: 5 n-6$ & $213.2 \pm 11.2$ & $212.9 \pm 17.5$ & 0.947 \\
\hline Total fatty acids & $17269 \pm 1641$ & $14055 \pm 1083$ & 0.120 \\
\hline
\end{tabular}

Fatty acid content, determined by GC/MS, in LV homogenates from 6-month old male and female 36 offspring of control (Con) and obese (Ob) dams. Con and Ob groups compared by Student's t-test with Holm-Sidak multiplicity correction. ${ }^{*} P<0.05$. Mean \pm SEM. 
bioRxiv preprint doi: https://doi.org/10.1101/2021.09.15.460457; this version posted September 16, 2021. The copyright holder for this preprint (which was not certified by peer review) is the author/funder. All rights reserved. No reuse allowed without permission.

\begin{tabular}{|c|c|c|c|}
\hline pmol/mg protein & Con & Ob & $P$ value (t-test) \\
\hline Males & $n=6$ & $n=5$ & \\
\hline 1,2-16:0/18:0DG & $7.1 \pm 2.1$ & $5.1 \pm 1.2$ & 0.997 \\
\hline 1,2-16:0/18:1DG & $34.3 \pm 13.8$ & $12.2 \pm 3.3$ & 0.434 \\
\hline 1,2-16:0/18:2DG & $22.4 \pm 9.3$ & $8.3 \pm 3.4$ & 0.881 \\
\hline 1,2-16:0/20:4DG & $4.4 \pm 2.1$ & $1.8 \pm 1.5$ & 0.997 \\
\hline 1,2-1,2-16:0/22:6DG & $11.7 \pm 3.9$ & $5.3 \pm 2.9$ & 0.997 \\
\hline 1,2-18:0/18:1DG & $9.4 \pm 4.0$ & $2.2 \pm 0.8$ & 0.997 \\
\hline 1,2-18:0/18:2DG & $12.7 \pm 4.0$ & $6.8 \pm 1.8$ & 0.997 \\
\hline 1,2-18:0/20:4DG & $55.1 \pm 12.8$ & $25.9 \pm 6.3$ & 0.128 \\
\hline 1,2-18:0/22:6DG & $9.7 \pm 3.3$ & $3.9 \pm 1.4$ & 0.997 \\
\hline 1,2-18:2/18:1DG & $52.3 \pm 21.9$ & $17.5 \pm 4.7$ & 0.033 \\
\hline 1,2-di16:0DGa & $12.3 \pm 3.5$ & $5.4 \pm 0.9$ & 0.997 \\
\hline 1,2-di18:0DGa & $5.2 \pm 2.4$ & $0.8 \pm 0.5$ & 0.997 \\
\hline 1,2-di18:1DGa & $34.4 \pm 16.2$ & $7.0 \pm 2.3$ & 0.178 \\
\hline 1,2-di18:2DGa & $28.0 \pm 9.7$ & $12.0 \pm 4.1$ & 0.816 \\
\hline Total DAGs & $305 \pm 105$ & $115 \pm 32$ & $0.084^{b}$ \\
\hline Females & $n=8$ & $\mathrm{n}=6$ & \\
\hline 1,2-16:0/18:0DG & $9.7 \pm 1.6$ & $9.8 \pm 1.8$ & 1.000 \\
\hline 1,2-16:0/18:1DG & $35.4 \pm 7.1$ & $29.6 \pm 4.7$ & 0.997 \\
\hline 1,2-16:0/18:2DG & $23.7 \pm 5.4$ & $19.0 \pm 3.1$ & 0.997 \\
\hline 1,2-16:0/20:4DG & $5.5 \pm 1.7$ & $4.9 \pm 1.4$ & 1.000 \\
\hline $1,2-1,2-16: 0 / 22: 6 D G$ & $15.2 \pm 3.5$ & $10.5 \pm 3.1$ & 0.997 \\
\hline 1,2-18:0/18:1DG & $11.5 \pm 2.6$ & $8.9 \pm 1.7$ & 0.999 \\
\hline 1,2-18:0/18:2DG & $21.9 \pm 3.2$ & $16.8 \pm 3.2$ & 0.997 \\
\hline 1,2-18:0/20:4DG & $56.5 \pm 7.0$ & $41.1 \pm 9.3$ & 0.421 \\
\hline 1,2-18:0/22:6DG & $18.8 \pm 4.8$ & $13.1 \pm 4.4$ & 0.997 \\
\hline 1,2-18:2/18:1DG & $58.0 \pm 10.5$ & $38.9 \pm 5.5$ & 0.147 \\
\hline 1,2-di16:0DGa & $13.5 \pm 2.1$ & $12.0 \pm 1.4$ & 0.999 \\
\hline 1,2-di18:0DGa & $5.2 \pm 0.6$ & $5.0 \pm 1.3$ & 1.000 \\
\hline 1,2-di18:1DGa & $31.4 \pm 8.1$ & $22.8 \pm 3.9$ & 0.958 \\
\hline 1,2-di18:2DGa & $42.5 \pm 8.5$ & $27.7 \pm 6.0$ & 0.456 \\
\hline Total DAGs & $353 \pm 67$ & $261 \pm 47$ & 0.313 \\
\hline
\end{tabular}

40

41

42

43

44

45

DAG content, determined by LC/MS, in LV homogenates from 6-month old male and female offspring of control (Con) and obese (Ob) dams. Con and Ob groups compared by Student's t-test with Holm-Sidak multiplicity correction. ${ }^{~} L o g$ transformed prior to statistical analysis. * ${ }^{*} \mathrm{P}<0.05$. Mean \pm SEM. 
bioRxiv preprint doi: https://doi.org/10.1101/2021.09.15.460457; this version posted September 16, 2021. The copyright holder for this preprint (which was not certified by peer review) is the author/funder. All rights reserved. No reuse allowed without permission.

47

\begin{tabular}{|l|l|l|l|}
\hline pmol/mg protein & Con & Ob & P value (t-test) \\
\hline Males & $\mathrm{n}=6$ & $\mathrm{n}=5$ & 0.852 \\
\hline 16:0Cer & $7.8 \pm 2.2$ & $3.5 \pm 1.0$ & 0.852 \\
\hline 18:0Cer & $5.1 \pm 1.4$ & $2.3 \pm 0.6$ & 0.390 \\
\hline $20: 0$ Cer & $13.5 \pm 5.3$ & $7.0 \pm 1.9$ & 0.181 \\
\hline $22: 0$ Cer & $16.6 \pm 4.6$ & $8.2 \pm 1.8$ & 0.852 \\
\hline $24: 0$ Cer & $5.5 \pm 1.3$ & $3.8 \pm 0.7$ & 0.777 \\
\hline $24: 1$ Cer & $8.1 \pm 1.9$ & $4.2 \pm 1.1$ & \\
\hline & & & 0.182 \\
\hline Total ceramides & $56.6 \pm 16.4$ & $29.0 \pm 6.8$ & \\
\hline & & & 1.000 \\
\hline Females & $\mathrm{n}=8$ & $\mathrm{n}=6$ & 1.000 \\
\hline 16:0Cer & $12.0 \pm 2.7$ & $11.4 \pm 2.2$ & 1.000 \\
\hline 18:0Cer & $9.1 \pm 1.8$ & $8.5 \pm 1.8$ & 1.000 \\
\hline $20: 0$ Cer & $14.7 \pm 3.1$ & $14.4 \pm 2.8$ & 1.000 \\
\hline $22: 0 C e r$ & $19.0 \pm 3.3$ & $20.2 \pm 5.0$ & 1.000 \\
\hline $24: 0 C e r$ & $8.3 \pm 1.8$ & $8.7 \pm 1.5$ & \\
\hline $24: 1$ Cer & $10.2 \pm 2.2$ & $10.1 \pm 2.1$ & 0.999 \\
\hline & & & \\
\hline Total ceramides & $73.3 \pm 14.5$ & $73.3 \pm 14.9$ & \\
\hline & & & \\
\hline & & & \\
\hline
\end{tabular}

48

49 Ceramide content, determined by LC/MS, in LV homogenates from 6-month old male and female 50 offspring of control (Con) and obese (Ob) dams. Con and Ob groups compared by Student's t-test with 51 Holm-Sidak multiplicity correction. Mean \pm SEM. 
bioRxiv preprint doi: https://doi.org/10.1101/2021.09.15.460457; this version posted September 16, 2021. The copyright holder for this preprint (which was not certified by peer review) is the author/funder. All rights reserved. No reuse allowed without permission. SUPPLEMENTARY FIGURE LEGENDS

54 heart. adult offspring of control dams.

Suppl. Fig. 1 Pparg is a critical node in the transcriptional effects of maternal obesity on the fetal

(A, B) Venn diagrams to show numbers and intersections of up- and down-regulated genes in male and female fetuses. (C, D) Cellular location and direct molecular interactions of differentially expressed, metabolism-related genes in E18.5 male and female fetuses of obese dams. (E) Regulator effects network identified from differentially expressed genes in male fetuses of obese dams. RNASeq data annotated and figures generated by Ingenuity Pathway Analysis. Red symbols indicate upregulated genes, green symbols indicate downregulated genes. Orange arrows indicate predicted activation, blue arrows indicate predicted inhibition.

Suppl. Fig. 2 Maternal obesity does not alter left ventricular systolic function or wall thickness in

$(A, B)$ Ejection fraction, $(C, D)$ fractional shortening, $(E, F)$ wall thickness in diastole and $(G, H)$ wall thickness at systole in male $(A, C, E, G)$ and female $(B, D, F, H)$ offspring of control and obese dams at 3, 6, 9 and 24 months after birth. Main effects of maternal obesity and postnatal age, and their interaction, were determined by two-way ANOVA and P values given in figure. Bars are mean \pm SEM. Symbols represent individual animals. $\mathrm{n}$ values given in bars.

Suppl. Fig. 3 Cardiac in vivo fatty acid and glucose uptake differ between female and male offspring

(A) Left ventricular $3 \mathrm{H}$-oleic acid clearance in female (Con $n=3$ ) and male (Con $n=7)$ offspring. Con and Ob groups by Student's t-test, Symbols represent individual offspring. (B,C) Left ventricular 8Ffluorodeoxyglucose clearance in female (Con $n=10)$ and male (Con $n=8)$ offspring of control and obese dams (B) Patlak plot, symbols represent mean \pm SEM values for all individuals within each group, at each normalized time point. (C) Histogram of mean \pm SEM clearance (gradient of Patlak plot) for each experimental group. $P$ values given in figure. Mean \pm SEM. 
Suppl. Fig. 1 Pparg is a critical node in the transcriptional effects of maternal obesity on the fetal heart.

A Upregulated genes

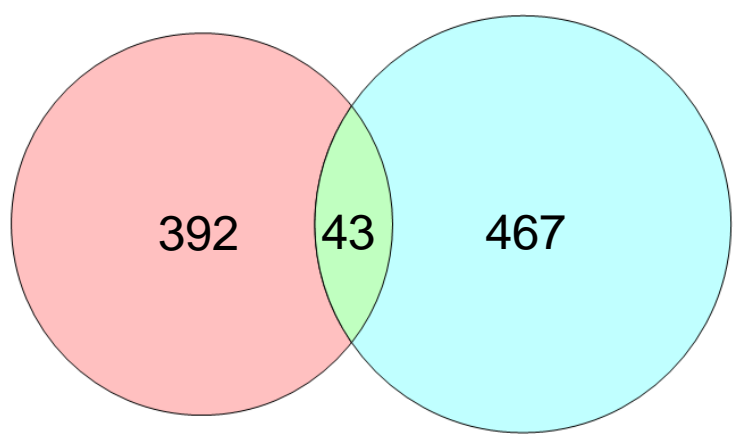

C

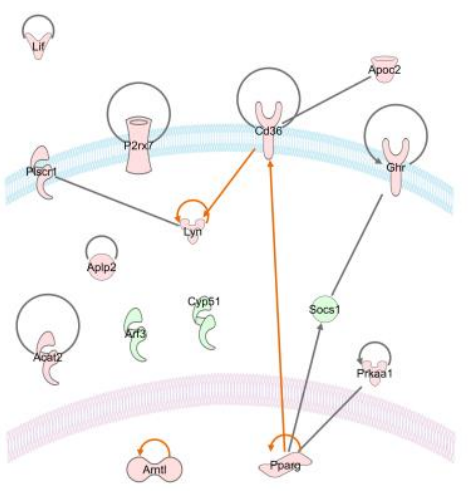

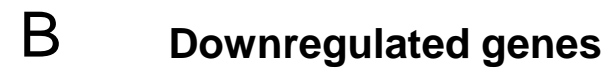

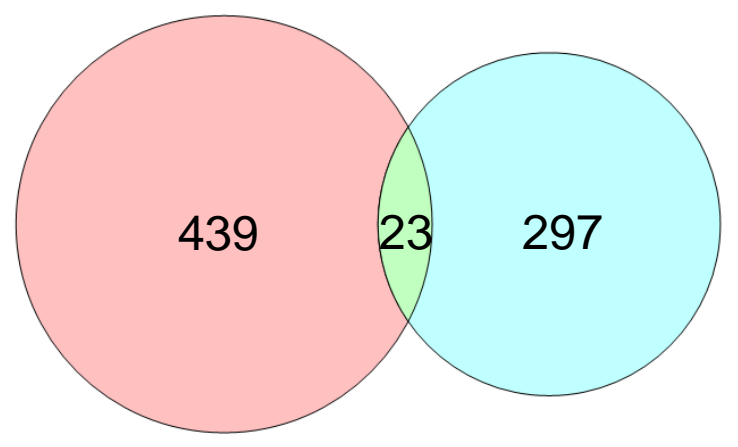

D

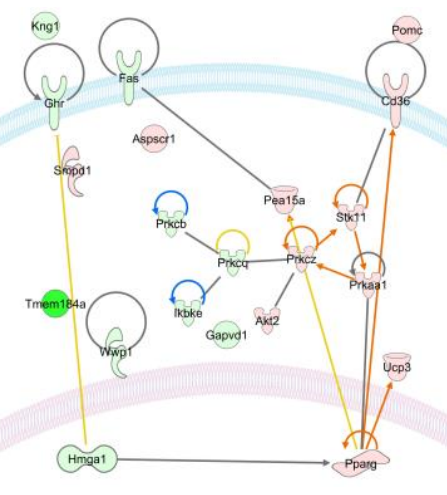

$\mathrm{E}$

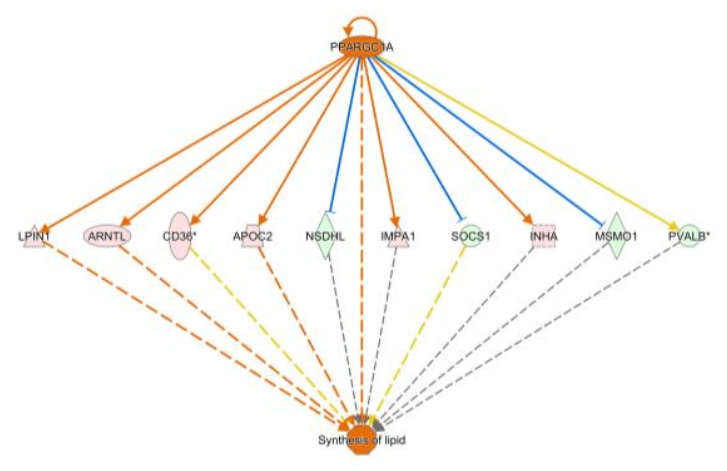


Suppl. Fig. 2 Maternal obesity does not alter left ventricular systolic function or wall thickness in adult offspring
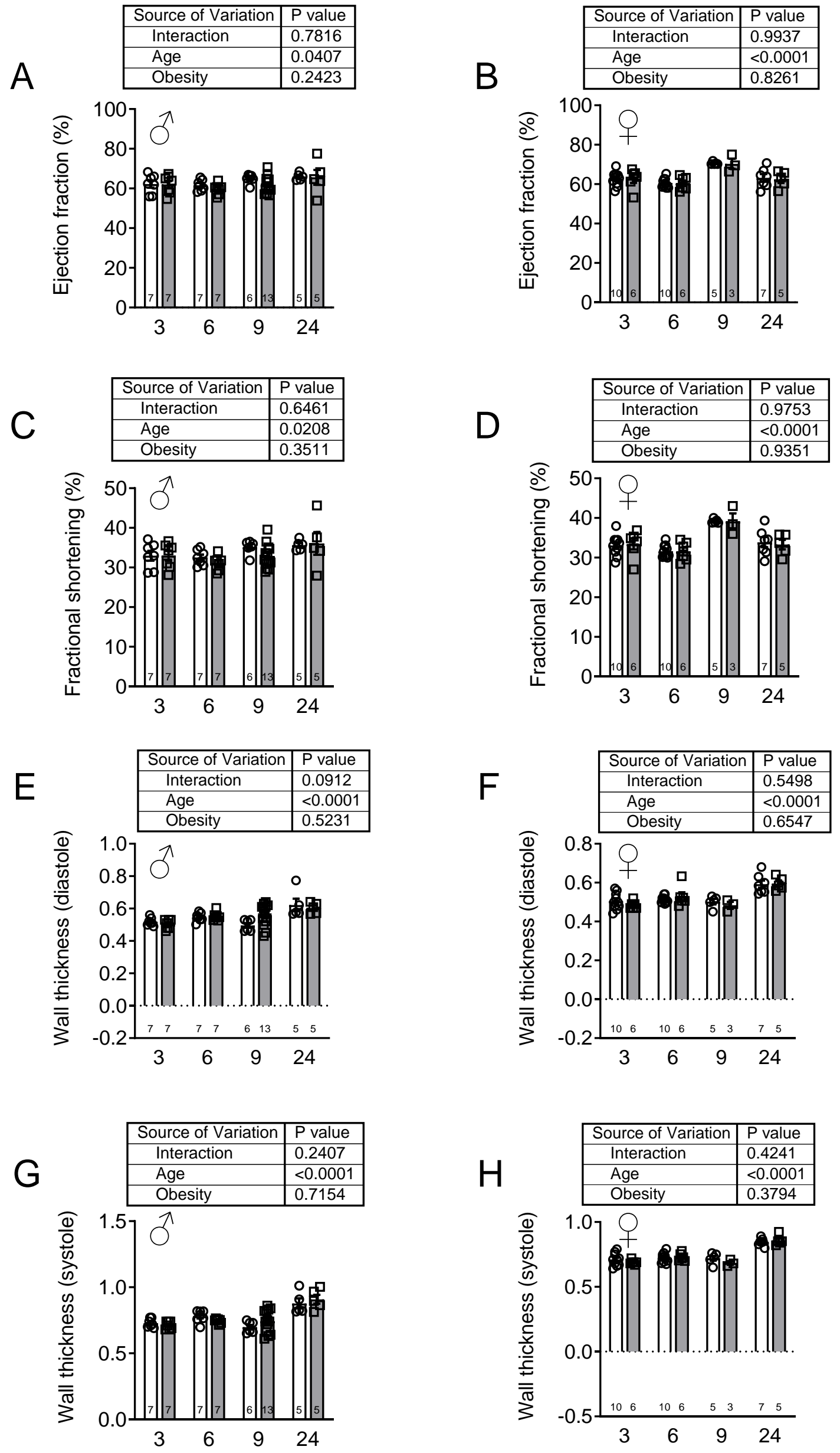
Suppl. Fig. 3 Cardiac in vivo fatty acid and glucose uptake differ between female and male offspring of control dams.

A

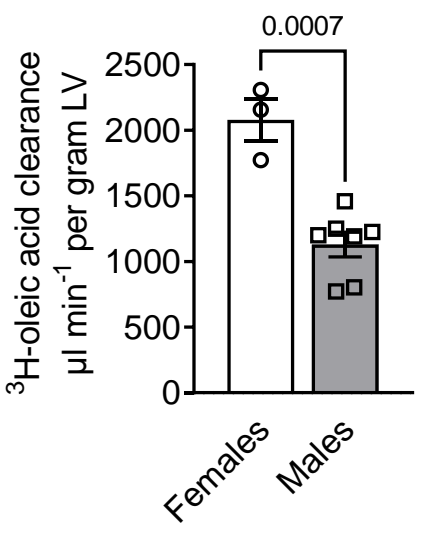

B

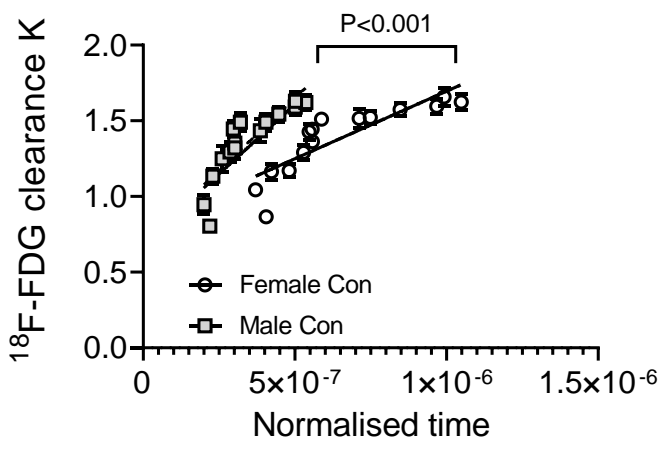

C

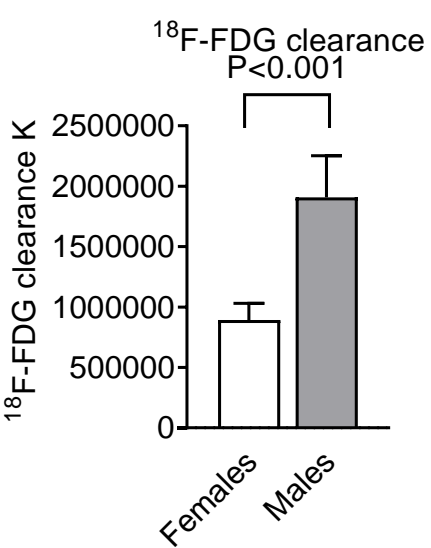


bioRxiv preprint doi: https://doi.org/10.1101/2021.09.15.460457; this version posted September 16, 2021. The copyright holder for this preprint (which was not certified by peer review) is the author/funder. All rights reserved. No reuse allowed without permission.

1

2 SUPPLEMENTARY METHODS

\section{Echocardiography}

Mice were anaesthetised ( $2 \%$ isoflurane, inhaled), placed in dorsal recumbency on a heated mat maintained at $37^{\circ} \mathrm{C}$ and hair removed from the thorax using a depilating cream. The heart was imaged in the parasternal short axis, at the level of the papillary muscle, by a trained operator blinded to the treatment group of the animal, using the Vevo 2100 system (VisualSonics). M-mode images of the left ventricle were collected across at least four consecutive cycles and used to measure ventricular wall thicknesses and chamber diameter in systole and diastole. Left ventricular internal volumes at systole and diastole were determined using the leading-edge method then ejection fraction and fractional shortening were calculated as indices of systolic function. Doppler velocimetry was used to determine peak mitral inflow in early $(\mathrm{E})$ and late $(\mathrm{A})$ diastole whilst tissue Doppler was used to determine peak ventricular wall displacement at the level of the mitral annulus, again in early $\left(E^{\prime}\right)$ and late $\left(A^{\prime}\right)$ diastole. $E / A, E^{\prime} / A^{\prime}$ and $E / E^{\prime}$ ratios were calculated as indices of ventricular diastolic function. Mice were recovered from anaesthesia following echocardiography and returned to their home cage.

\section{RNA sequencing}

Sequencing libraries with unique barcodes were constructed from $100 \mathrm{ng}$ of total RNA using the KAPA Stranded mRNA-Seq kit (Kapa Biosystems, Wilmington, MA) according to the manufacturer's protocol. Individual cDNA libraries were quantified by qPCR. Pooled libraries were used to generate clusters by cBot with version 3 reagents (Illumina, San Diego, CA). Multiplex paired-end ( $2 \times 100$ base) sequencing was performed on the HiSeq 2500 Sequencing System with version 3 SBS chemistry (Illumina). Sequencing reads were demultiplexed using the CASAVA pipeline (IIlumina) and then aligned to the Mus musculus reference genome (mm10) using STAR version 2.5.3a in Partek Flow (Partek, St. Louis, MO). Aligned reads were quantified using the Expectation/Maximization algorithm in Partek Flow with RefSeq transcripts from NCBI annotation release 84. Transcripts with zero read counts across all samples were removed prior to performing normalization of read counts using the Trimmed Mean of 
bioRxiv preprint doi: https://doi.org/10.1101/2021.09.15.460457; this version posted September 16, 2021. The copyright holder for this preprint (which was not certified by peer review) is the author/funder. All rights reserved. No reuse allowed without permission.

included for comparing expression in Ob vs. Con, separately in male and female fetuses. The Gene-

Specific Analysis in Partek Flow was used for differential expression analysis, in which the best statistical model was identified for each transcript based on the normalized read counts of that transcript and the best model was used to produce the fold change, $P$ values and $P$ values adjusted by the method of Benjamini and Hochberg ${ }^{47}$.

Differentially expressed mRNAs were functionally annotated in silico using Ingenuity Pathway Analysis (IPA) software (Qiagen). Downstream biological processes predicted to be affected by maternal obesity were identified using an unbiased approach based on significant enrichment with differentially expressed genes. The direction of expression change of mRNAs within each gene set was used to predict overall activation status of the pathway or function, by calculating a z-score, such that negative z-scores represented inhibited pathways and positive z-scores represented activated pathways. Functions were filtered for further investigation based on a threshold of $z$-score $>|1.7|$ and ranked by significance level (P-value). Downstream functions commonly affected by maternal obesity in both female and male fetuses were identified using unsupervised comparative analysis in IPA. Unsupervised upstream regulator analysis within IPA was also used to identify key molecules (e.g. transcription factors) predicted to cause the observed transcriptional effects of multiple differentially expressed genes.

Targeted lipidomic analyses

For fatty acid quantification, frozen ventricular tissue was homogenised in hepes-tris buffered saline solution then lipids were extracted using a liquid-liquid extraction method, as described (Chassen et al, 2018). Briefly, an aliquot of ventricle homogenate was deproteinised by addition of methanol, with vortexing, then centrifuged $(500 \mathrm{~g}, 15 \mathrm{~min}$, at room temperature). The supernatant solution was transferred to a glass vial, water and dichloromethane were added to extract lipids, vortexed and 
bioRxiv preprint doi: https://doi.org/10.1101/2021.09.15.460457; this version posted September 16, 2021. The copyright holder for this preprint (which was not certified by peer review) is the author/funder. All rights reserved. No reuse allowed without permission. centrifuged. The polar lipid lower layer was separated and dichloromethane extraction was repeated with the upper aqueous layer. Combined lipid layers were dried under $\mathrm{N}_{2}$, resuspended in ethanol then spiked with an internal FA standard solution. Lipids were saponified with $1 \mathrm{M} \mathrm{NaOH}$ at $90^{\circ} \mathrm{C}$ for $1 \mathrm{hr}$, neutralised, extracted into isooctane and derivatized using pentafluorobenzyl bromide and diisopropylethalamine in acetonitrile. The final fatty acid extract was resuspended in isooctane for GCMS analysis. Samples were separated on a HP-5MS capillary column $(30 \mathrm{~m}, 0.25 \mathrm{~mm}, 0.10 \mathrm{~mm}$ film thickness, Agilent), subjected to mass spectrometry then identified and quantified based on $\mathrm{m} / \mathrm{z} \mathrm{ratios}$ and peak heights, respectively ${ }^{48}$.

For quantification of ceramides and diacylglycerol (DAG) species, heart samples homogenized in 900 $\mu \mathrm{L}$ water and an aliquot $(20 \mu \mathrm{L})$ taken for protein concentration. Methanol $(900 \mu \mathrm{L})$ was added to the homogenized sample $(750 \mu \mathrm{L})$. After the addition of 15:0/18:1( $\left.\mathrm{d}_{7}\right)$-DAG (80 pmol) and 12:0-ceramide (80 pmol) as internal standards, lipid extraction was performed by the addition of methyl-tert-butyl ether ( $3 \mathrm{~mL}$ ) according to Matyash et al ${ }^{49}$. The organic phase was dried under a stream of nitrogen gas and resuspended in $400 \mu \mathrm{L}$ of a mixture of $70 / 30(\mathrm{v} / \mathrm{v})$ hexane:methylene chloride. Samples were injected into an HPLC system connected to a triple quadrupole mass spectrometer (Sciex 2000 QTRAP, Framingham, MA) and normal phase chromatography with a HILIC column (100x2.1 mm, Kinetex HILIC $2.6 \mu \mathrm{m}$, Phenomenex) was used to separate lipids by class ${ }^{50}$. Mass spectrometric analysis was performed in the positive ion mode using multiple-reaction monitoring (MRM) of DAG and ceramide molecular species and the internal standards. Quantitation was performed using stable isotope dilution with a standard curve for DAGs and ceramides and results were normalized to protein content. All lipid measurements were expressed relative to tissue protein content, determined by bicinchoninic acid assay. 